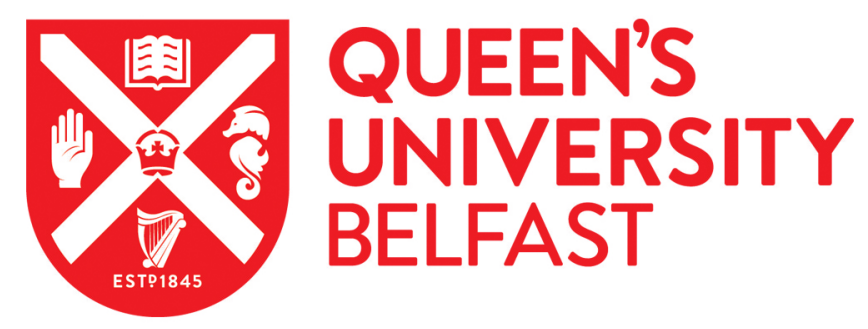

\title{
An assessment of wind energy potential in the Beibu Gulf considering the energy demands of the Beibu Gulf Economic Rim
}

Chen, X., Foley, A., Zhang, Z., Wang, K., \& O'Driscoll, K. (2020). An assessment of wind energy potential in the Beibu Gulf considering the energy demands of the Beibu Gulf Economic Rim. Renewable and Sustainable Energy Reviews, 119, [109605]. https://doi.org/10.1016/j.rser.2019.109605

Published in:

Renewable and Sustainable Energy Reviews

Document Version:

Peer reviewed version

Queen's University Belfast - Research Portal:

Link to publication record in Queen's University Belfast Research Portal

Publisher rights

Copyright 2019 Elsevier.

This manuscript is distributed under a Creative Commons Attribution-NonCommercial-NoDerivs License

(https://creativecommons.org/licenses/by-nc-nd/4.0/), which permits distribution and reproduction for non-commercial purposes, provided the author and source are cited.

\section{General rights}

Copyright for the publications made accessible via the Queen's University Belfast Research Portal is retained by the author(s) and / or other copyright owners and it is a condition of accessing these publications that users recognise and abide by the legal requirements associated with these rights.

Take down policy

The Research Portal is Queen's institutional repository that provides access to Queen's research output. Every effort has been made to ensure that content in the Research Portal does not infringe any person's rights, or applicable UK laws. If you discover content in the Research Portal that you believe breaches copyright or violates any law, please contact openaccess@qub.ac.uk. 
\& Sustainable Energy Reviews

Elsevier Editorial System(tm) for Renewable

Manuscript Draft

Manuscript Number: RSER-D-18-03321R4

Title: An assessment of wind energy potential in the Beibu Gulf considering the energy demands of the Beibu Gulf Economic Rim

Article Type: VSI:Bryden 2018

Section/Category: Wind

Keywords: Beibu Gulf; Wind energy; Renewable energy; Wind power; Wind climate

Corresponding Author: Dr. Xinping Chen, Ph.D.

Corresponding Author's Institution: National Marine Hazard Mitigation Service

First Author: Xinping Chen, Ph.D.

Order of Authors: Xinping Chen, Ph.D.; Aoife Foley; Zenghai Zhang; Kaimin Wang; Kieran O'Driscoll

Abstract: The Beibu Gulf Economic Rim of China is a key economic region in western China as demonstrated by the "Beibu Gulf Cities Development Project" (2017) that plans to build a "Blue Livable Gulf" to balance environmental protection while providing sustainable economic development. This region has significant energy needs and is predicted to exhibit rapid growth in the future.

By means of meteorological observations located at seven islands, a comprehensive statistical analysis on wind energy potential in the northern coastal part of the Beibu Gulf is conducted in this study. Specifically, wind speed, Weibull parameters, wind power density, as well as wind directions on various timescales are analyzed. The analysis shows that annual mean wind power density during 2010-2017 at 100m above mean sea level was, respectively, 605.6, 542.0, 368.0, 282.0, 265.6, 87.6 and $321.5 \mathrm{Wm}-2$ at the seven sites, with average value of $353.2 \mathrm{Wm}-2$.

Evidently, wind power potential demonstrates intra-annual variability, with greatest values occurring in December, while another peak value is observed in July. Wind speeds are lowest in May with another trough occurring in August. The data also display weak inter annual variability. The prevailing wind directions in the rim are mainly from opposing directions of $\mathrm{N}$ (winter and autumn) and $\mathrm{S}$ (summer).

Response to Reviewers: The authors wish to thank reviewers for their constructive comments, which have greatly helped improve the quality of the present manuscript. We have carefully considered all remarks. Below, please find detailed responses to the comments. We would also like to extend our appreciation to the editors for their efforts.

Reviewer comments and author responses:

Reviewer \#1: The authors have improved the manuscript in response to the reviewers' comments. This reviewer apologises to the author for confusing the Vietnamese island of "Dao Tran" with one of the islands within the 
study. The manuscript can be accepted in its current form, however I am not entirely convinced that wind speed and wind power variability

estimates will not be affected by 30\% data loss. The authors could include a comment to this effect, e.g. "Estimates of wind speed and wind power variability may be influenced by gaps in the data", I leave it to the authors to decide on this.

Response: Thank you very much for your comments.

The authors have taken this suggestion and comment on the influence of the data gap in the conclusion. Furthermore, a new subsection has been added to the paper to state the limitation of the present analysis due to this data loss, and also to recommend follow-up work and further analysis. Please see Subsection 3.5 ( P. 11-12) and the last paragraph of Conclusions (P. 20 Lines 28-30, P. 21 Lines 1-6).

Reviewer \#2: Thank you for addressing my comments. The analysis is still limited by the number, location and height of the measurement locations, and subsequent analysis of collected data. The level of scientific merit is low, and therefore I do not believe that the study in its present form is suitable for publication.

Response: The authors thank the reviewer for your comments.

Concerning the limitation by number, location and height of measurement locations, a new subsection has been added to the paper to state the limitation of the present analysis due to the data loss and also recommending follow-up work and further analysis. Please see Subsection 3.5 (P. 11-12) and the last paragraph of Conclusions (P. 20 Lines 28-30, P. 21 Lines 1-6).

Editor in Chief: You are to add a subsection into the methodology called 'Limitations of the analysis,' which states that 'The authors wish to state for the record that analysis is meant as a first pass only at estimating the viable offshore wind resource in order to highlight the vast offshore wind resource available. There was a data loss of approximately 30\%, which means that better and more reliable datasets are needed for the region. This is a recommendation of this work for followup work. Next the analysis is also limited by the hub height and measurement locations. However, once better datasets are available in the region, further analysis will be undertaken using the latest offshore wind turbine parameters.' Once this section has been added and the recommendation also added to the conclusion, please resubmit the paper. Response: Thank you very much for your comments and suggestion. We have revised the manuscript accordingly. The new subsection and the recommendation have been added to the paper. Please see Subsection 3.5 (P. 11-12) and the last paragraph of Conclusions (P. 20 Lines 28-30, P. 21 Lines 1-6). 
The authors wish to thank reviewers for their constructive comments, which have greatly helped improve the quality of the present manuscript. We have carefully considered all remarks. Below, please find detailed responses to the comments. We would also like to extend our appreciation to the editors for their efforts.

Reviewer comments and author responses:

Reviewer \#1: The authors have improved the manuscript in response to the reviewers' comments. This reviewer apologises to the author for confusing the Vietnamese island of "Dao Tran" with one of the islands within the study. The manuscript can be accepted in its current form, however I am not entirely convinced that wind speed and wind power variability estimates will not be affected by $30 \%$ data loss. The authors could include a comment to this effect, e.g. "Estimates of wind speed and wind power variability may be influenced by gaps in the data", I leave it to the authors to decide on this.

Response: Thank you very much for your comments.

The authors have taken this suggestion and comment on the influence of the data gap in the conclusion. Furthermore, a new subsection has been added to the paper to state the limitation of the present analysis due to this data loss, and also to recommend follow-up work and further analysis. Please see Subsection 3.5 ( P. 11-12) and the last paragraph of Conclusions (P. 20 Lines 28-30, P. 21 Lines 1-6). 
Reviewer \#2: Thank you for addressing my comments. The analysis is still limited by the number, location and height of the measurement locations, and subsequent analysis of collected data. The level of scientific merit is low, and therefore I do not believe that the study in its present form is suitable for publication.

Response: The authors thank the reviewer for your comments.

Concerning the limitation by number, location and height of measurement locations, a new subsection has been added to the paper to state the limitation of the present analysis due to the data loss and also recommending follow-up work and further analysis. Please see Subsection 3.5 (P. 11-12) and the last paragraph of Conclusions (P. 20 Lines 28-30, P. 21 Lines 1-6).

Editor in Chief: You are to add a subsection into the methodology called 'Limitations of the analysis,' which states that 'The authors wish to state for the record that analysis is meant as a first pass only at estimating the viable offshore wind resource in order to highlight the vast offshore wind resource available. There was a data loss of approximately 30\%, which means that better and more reliable datasets are needed for the region. This is a recommendation of this work for follow-up work. Next the analysis is also limited by the hub height and measurement locations. However, once better datasets are available in the region, further analysis will be undertaken using the latest offshore wind turbine parameters.' Once this section has been 
added and the recommendation also added to the conclusion, please resubmit the paper.

Response: Thank you very much for your comments and suggestion. We have revised the manuscript accordingly. The new subsection and the recommendation have been added to the paper. Please see Subsection 3.5 (P. 11-12) and the last paragraph of Conclusions (P. 20 Lines 28-30, P. 21 Lines 1-6). 


\title{
An assessment of wind energy potential in the Beibu Gulf considering the
} energy demands of the Beibu Gulf Economic Rim

\author{
Xinping Chen ${ }^{\mathrm{a},{ }^{*}}$, Aoife Foley ${ }^{\mathrm{b}}$, Zenghai Zhang ${ }^{\mathrm{c}}$, Kaimin Wang ${ }^{\mathrm{d}}$, Kieran O'Driscoll ${ }^{\mathrm{e}}$ \\ ${ }^{a}$ National Marine Hazard Mitigation Service of State Oceanic Administration, Beijing 100194, China. \\ ${ }^{b}$ School of Mechanical and Aerospace Engineering, Queen's University Belfast, Belfast BT9 5AH, \\ Northern Ireland, UK. \\ ${ }^{c}$ National Meteorological Center of China Meteorological Administration, Beijing 100081, China. \\ ${ }^{d}$ Shenzhen forecasting center, Shenzhen, Guangdong Province, China. \\ ${ }^{e}$ School of Natural and Built Environment, Queen's University Belfast, Belfast BT9 5AH, Northern \\ Ireland, UK.
}

\section{Abstract}

The Beibu Gulf Economic Rim of China is a key economic region in China as demonstrated by the "Beibu Gulf Cities Development Project" (2017) that plans to build a "Blue Livable Gulf" to balance environmental protection while providing sustainable economic development. This region has significant energy needs and is predicted to exhibit rapid growth in the future.

By means of meteorological observations located at seven islands, a comprehensive statistical analysis on wind energy potential in the northern coastal part of the Beibu Gulf is conducted in this study. Specifically, wind speed, Weibull parameters, wind power density, as well as wind directions on various timescales are analyzed. The analysis shows that annual mean wind power density during 2010-2017 at 100m above mean sea level was, respectively, 605.6, 542.0, 368.0, 282.0, 265.6, 87.6 and $321.5 \mathrm{Wm}^{-2}$ at the seven sites, with average value of $353.2 \mathrm{Wm}^{-2}$. Evidently, wind power potential demonstrates intra-annual variability, with greatest values occurring in December, while another peak value is observed in July. Wind speeds are lowest in May with another trough occurring in August. The data also display weak inter annual variability. The prevailing wind directions in the rim are mainly from opposing directions of $\mathrm{N}$ (winter and autumn) and $\mathrm{S}$ (summer).

Keywords: Beibu Gulf, Wind energy, Renewable energy, Wind power, Wind climate

\footnotetext{
* Corresponding author.

Email address: xinp.chen@foxmail.com (Xinping Chen)
} 


\section{Introduction}

The use of wind power as an alternative energy source, both on- and off-shore, has increased rapidly over the last 10 years [1-4]. The offshore market is expected to grow at a higher pace than the onshore market, representing about one quarter of the total new wind power installations by 2020 [3]. One significant development in recent years is the spectacular drop in offshore wind power prices, thus making offshore wind power as competitive as fossil fuels and nuclear power [5]. Besides the cost of wind power, renewables like wind can also provide solutions to relieve some key environmental and social challenges, including improving energy security, creating more jobs, reducing public health and air pollution problems, and mitigating against greenhouse gas emissions (GHG) [3, 6].

When comparing development of wind energy sources, offshore sources have been shown to be superior to onshore sources in a number of ways [7, 8]. For example, offshore wind speeds are usually greater and more steady, leading to less turbulence effects than those on land at nearby sites $[9,10]$. A number of studies have assessed offshore wind characteristics and wind power potential, either globally or at specific sites [e.g., 11-35], providing fundamental information for offshore wind power exploitation, for example, spatial and potential variability of wind energy potential display for different offshore regions.

\subsection{The development of wind energy in China}

China possesses and can potentially harness abundant quantities of onshore and offshore wind energy. It has been reported by the Global Wind Energy Council (GWEC) [5] that as the driver of global market growth for most of the last decade, China installed 21.2 GW of onshore wind and 1.8 GW of offshore wind in 2018, representing $45 \%$ and $40 \%$ of global market share respectively. In 2018, the second largest market was the US with 7.6 GW of new onshore installations, followed by Germany $(2.4 \mathrm{GW})$, India $(2.2 \mathrm{GW})$ and Brazil $(1.9 \mathrm{GW})$. For the offshore market in 2018, China took the lead for the first time, followed by the United Kingdom with 1.3 GW. Germany took the third place $(0.9 \mathrm{GW})[5]$. 
Although China is the world's largest wind power market in both new and cumulative installations, China also has a very large population of about 1.4 billion. In particular, more than half the people in China live in the eastern coastal region, where the economy is relatively developed, thereby leading to a huge energy demand. Therefore, compared with other countries such as the USA, United Kingdom and Germany, new installations in both onshore and offshore wind market is actually much lower on a per capita basis, indicating that China still needs to strive to develop wind energy exploitation, particularly for nearshore and offshore wind energy.

Additionally, China has a very long coastline, approximately 18,000 km running from the Bohai Sea in the north to the Beibu Gulf in the south, adjacent to a 12-nautical-mile territorial sea with depths mostly less than $100 \mathrm{~m}$. This means that, firstly, offshore wind is a very viable solution located close to the major coastal urban areas of Tianjin, Shanghai, Guangzhou, Shenzhen and so on, with their many millions of citizens. Secondly, wind power resources vary spatially and temporally: wind power densities along the coast of the Chinese Seas regions range from $200 \mathrm{Wm}^{-2}$ to $1000 \mathrm{Wm}^{-2}$ [36-39], which can also be realized from the Global Wind Atlas (https://globalwindatlas.info/). The potential for offshore wind power has been examined for some coastal regions of China. For example, wind power potential was assessed for the Pearl River Delta region [41] and for Hongkong [29, 42-44]; the nearshore wind energy resources off the Shenzhen coast was carefully evaluated [45]; while a model-based climatology analysis was made for wind power resources over the Bohai Sea and the Yellow Sea [46]. Furthermore, previous studies have shown that even in relatively small offshore areas, wind energy potential can display spatial and temporal differences $[35,45]$. Therefore, before selecting a site to build wind power plants, it is an essential and important first step to conduct a precise survey and assessment of wind energy resources around the region, especially for the offshore region where observational data are still rare and good quality information is limited.

The area of interest in this study is off the coast of Guangxi Zhuang Autonomous Region, located in the Beibu Gulf Economic Rim (BGER) of China, located in the South China Sea (see Figure 1). This is one of the least developed regions of China, 
1 and especially for a coastal region. As an important part of the "China Western

2 Development Strategy", in 2017, the central government of China has sanctioned the

3 "Beibu Gulf Cities Development Project" (BGCD project). The project aims to build 3

4 "City Centre Circles", 2 "City Development Roles" and 1 "Blue Liveable Gulf" (the

5 Beibu Gulf). Various infrastructures will be built, and a large amount of manpower,

6 resources and capital investments and other invisible privileges needed are planned to

7 promote the development of the whole BGER and to thoroughly shake off the relative 8 poverty and backwardness of this region.

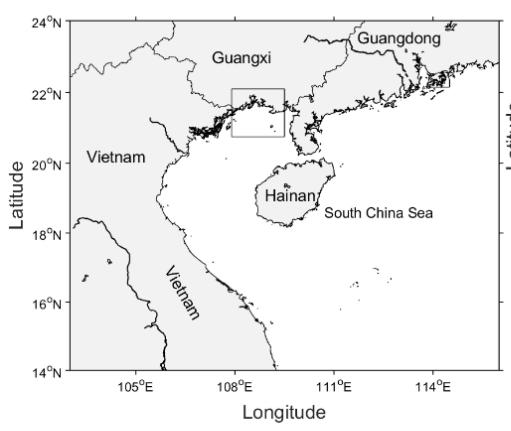

10Figure 1 : Area of the study relative to the northern South China Sea (left) and geographic locations of the 11 seven meteorological sites in red crosses (+ right). 

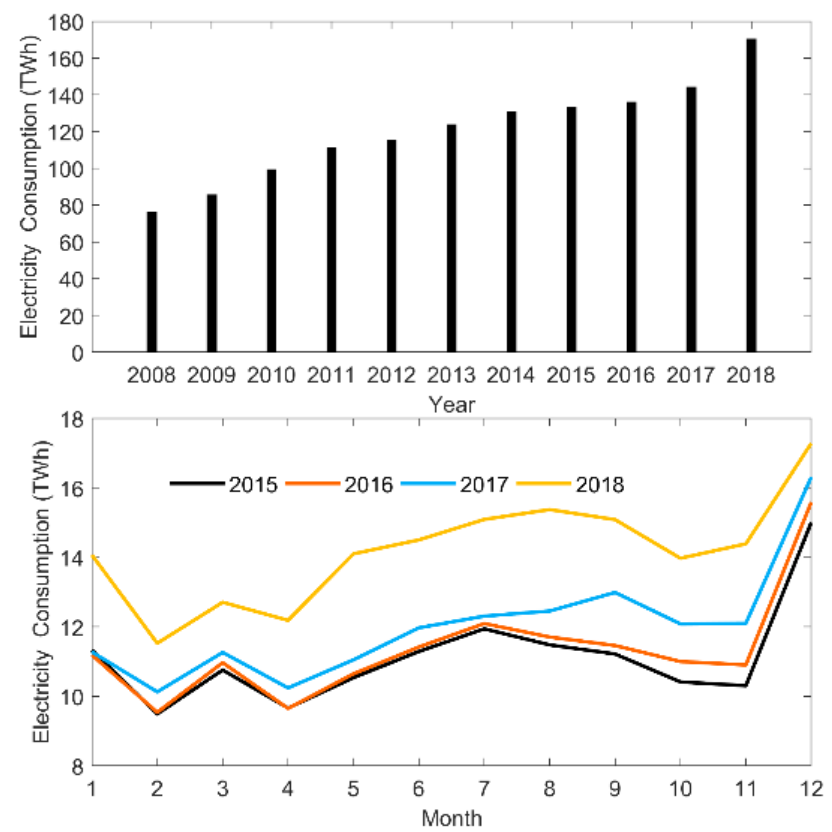

Figure 2: (Top) Electricity consumption of the Guangxi Zhuang Autonomous Region (Guangxi Formatted: Space Before: 0.5 line 4 province) for the period 2008-2017; (Bottom) monthly electricity consumption of Guangxi in 2015, 52016 and 2017. (Data resource: China Energy Statistical Yearbook (2008-2017) [47]).

Electricity consumption of Guangxi province in the past 11 years was analyzed to reflect the energy demand for this rim. As shown in Figure 2, the electricity consumption in Guangxi and Hainan provinces has been rising continuously for the past 11 years [47]. Furthermore, since the BGCD project was sanctioned in 2017, the growth rate of the electricity consumption in Guangxi province has risen rapidly, exceeding expectations. In 2018, electricity consumption in Guangxi had reached 170.28TWh, with growth rate up 17.84\% compared with the value of 2017 (144.23 TWh), which is much higher than the growth rate of China (8.5\%). From the official report, energy consumption in Zhanjiang municipal city in this rim was, $10.80 \mathrm{TWh}$ and 18.15 TWh in 2016 and 2017, respectively, and its year-on-year growth rate was $7.8 \%$ and $18.4 \%$, respectively, with the latter leaping to the top in Guangdong province (Zhanjiang is a municipal city of Guangdong province). Overall, electricity consumption in this rim has rapidly grown, especially from 2017 , reflecting the rapid 19 growth of energy demand in the rim. 
However, air pollution and smog have already occurred in many regions of China, especially in eastern coastal regions, including Beijing, Tianjin, and Hangzhou. Development in Eastern China has followed the well-worn global routine of priority for economic growth and expansion, inevitably resulting in air pollution, thus sacrificing the environment without consideration of necessary steps to address the resultant environmental and pollution problems. This approach has resulted in many painful lessons for China, generating serious dialogue and deep thought, thereby compelling China to express its resolute determination to avoid further pollution in less developed regions such as the western region of China. China is now implementing a sustained developmental strategy to accelerate the change of energy structure, particularly with a view to increasing the share of clean sources in its energy mix [48].

The BGER is one such new region to be developed in China, and has been endowed to construct and provide non-polluting industry and tourism. For example, Hainan Island (province), an important part of the BGER, recently officially published the "Implementation plan of National pilot ecological zone (Hainan Province) of China" in May 2019. This initiative clearly points out that Hainan plans to build a "Clean Energy Island", including measures leading to the step by step prohibition of the selling of all petrol vehicles.

At the outset of action formulation and plan development for the BGER, clean reen energy, including wind energy, will be the primary consideration. However, wind energy development in this zone has fallen far behind. In 2017, more than 1.16 GW of additional offshore wind power capacity was installed in Chinese coastal areas, while there has been no installed capacity in the Beibu Gulf up to the end of 2017 [47]. Thus, especially because of inadequate knowledge and understanding of coastal wind characteristics, the exploitation of coastal wind energy resources in the region is still lacking.

To assist in the venture of optimal harvesting and utilization of wind power, this paper presents a careful and comprehensive statistical assessment on wind field and energy potential with detailed resource characterization for the period 2010 to 2017, 
by means of measurement data collected from seven meteorological stations on coastal islands in the Beibu Gulf. The present study aims to provide insight toward understanding of wind energy potential required in exploring wind energy resources in the study area, in terms of wind speed variation, Weibull parameters and wind power density, as well as wind direction on various timescales. Additionally, to discuss the specific ability of energy development within the region, this study also provides the insight to meet the energy demand for the rim.

\section{Wind data measurement and adjustment}

In this study, data measured at seven meteorological stations on offshore islands and acquired by the CMA, are available for the region. The geographic locations of these seven meteorological stations are given in Figure 1. Before the stations were built, the site selections were fully demonstrated, following related standards and specifications, and data records were carefully checked by the data center of CMA, to ensure that the data are no problem for further analyses. Data collected at the stations are representative of wind climate for different areas of the study region. Data are gathered mainly to monitor atmospheric changes in the region, including forecasting and scrutiny of meteorological and environmental issues, etc. The stations are located at different heights above mean sea level (MSL), while the anemometer for each station is installed at $10 \mathrm{~m}$ height above the surface of each station ground.

In China, each station for surface meteorological measurement must be followed the standard of the "Specifications for surface meteorological observation" (QX/T 45-2007) that published in 2007 (the modified new version is published in 2017 (GB/T 35221-2017)), which specified that surface meteorological stations must be located in the relatively flat and open terrain so as to be representative of relatively large local meteorological characteristics. The stations used in this study meet the standard. The wind monitors at the stations are high performance wind monitor sensors (RM Yong 5106) with blade helicoid propellers, purchased from R.M. Young.

The wind data adapted in the present study include wind speed and direction parameters over the period January 2010 to December 2017. Wind speed parameters 
were sampled every $1 \mathrm{~s}$ and averaged over $1 \mathrm{~min}$. Wind direction data was recorded 6 times per minute, and also averaged over $1 \mathrm{~min}$. The stations at QC, DM, SD, DY and $\mathrm{BH}$ are located very close to shore, of which QC and DM are located in the mouth of Qingzhou Bay; SD is located in Zhenzhu Bay; DY is located near Fangcheng Port. $\mathrm{BX}$ is further offshore, and $\mathrm{ZZ}$ and $\mathrm{XY}$ are located furthest from shore.

The sensor height at which wind data is measured at the different stations is shown in Table 1 . We note the large variability in recorded wind speed, and also that wind speed will vary as a function of recorded height. To extrapolate recorded wind data to likely turbine hub height, hub height is set at $100 \mathrm{~m}$ above MSL for this study, unless otherwise stated. A number of earlier studies have employed mathematical models representing height variability of wind speed, of which the log-law model has been most commonly employed [49]. The simple power-law model is frequently

Table 1: List of measurement sites in the Guangxi coastal region with some fundamental mean wind and energy characteristics. Hourly collected observational data covered for the period August 2009 to the end of 2017. Table No. of observations represents the valid number of observations used in the study for each station. Total number of the hours over the study period is 70128. Height (m) in the table represents the wind sensor height above the mean sea level at each station. Main wind characteristics were statistically calculated, including wind speed, $V\left(\mathrm{~ms}^{-1}\right)$; Weibull parameters, $\kappa$ and $c\left(\mathrm{~ms}^{-1}\right) ; V_{m p}\left(\mathrm{~ms}^{-1}\right) ; V_{\max . E}\left(\mathrm{~ms}^{-1}\right)$; wind power, $P\left(\mathrm{~W} \mathrm{~m}^{-2}\right)$.

\begin{tabular}{|c|c|c|c|c|c|c|c|}
\hline Site & BX & DY & SD & QC & DM & ZZ & XY \\
\hline No. of observations & 53216 & 57908 & 61610 & 59657 & 50221 & 70001 & 54017 \\
\hline Height & 17.1 & 13.5 & 20.6 & 21.0 & 28.0 & 65.7 & 42.8 \\
\hline $\boldsymbol{V}_{\text {mean }}$ & 7.6 & 7.2 & 6.1 & 6.0 & 5.8 & 4.0 & 5.7 \\
\hline $\boldsymbol{\kappa}$ & 1.8 & 1.7 & 1.6 & 1.9 & 1.8 & 1.9 & 1.5 \\
\hline $\boldsymbol{c}$ & 8.6 & 8.0 & 6.8 & 6.8 & 6.6 & 4.6 & 6.4 \\
\hline
\end{tabular}




\begin{tabular}{|c|c|c|c|c|c|c|c|}
\hline $\boldsymbol{V}_{\boldsymbol{m p} \boldsymbol{p}}$ & 7.8 & 7.1 & 5.8 & 6.1 & 5.8 & 3.9 & 5.3 \\
\hline $\boldsymbol{V}_{\text {max.E }}$ & 9.4 & 8.8 & 7.7 & 7.6 & 7.3 & 5.3 & 7.3 \\
\hline $\boldsymbol{P}_{\text {mean }}$ & 605.6 & 542.0 & 368.0 & 282.0 & 265.6 & 87.6 & 321.5 \\
\hline
\end{tabular}

\section{3. Analytical methods}

To provide the statistical analysis of wind characteristics and the assessment of wind energy potential sources associated with wind energy exploitation, several analytical methods are applied and briefly described below.

\subsection{Weibull distribution function}

Probability distribution models are commonly used to fit wind speed distributions over a time period and to obtain a clear view of the available wind potential for a region. A large number of different distribution models have been proposed for statistically analysing both wind characteristics and potential wind as energy assessment. Amongst all the available probability distribution functions, the Weibull probability distribution functions, particularly the two-parameter Weibull function, are commonly used and widely adopted for wind energy applications, not only due to their great flexibility and simplicity but also because they can provide a good representation of recorded wind data $[29,35,50,54-57]$. Therefore, the two-parameter Weibull distribution model was utilized for the assessment of wind energy potential sources in this study.

The general form of the two-parameter Weibull function can be characterized by the Probability Density Function (PDF), $f(v)\left(f(v)=\left(\frac{k}{c}\right)\left(\frac{v}{c}\right)^{\kappa-1} \exp \left(\left[-\left(\frac{v}{c}\right)^{k}\right]\right)\right)$, and cumulative distribution function, $F(v)$. Here, $v$ is wind speed in $\mathrm{ms}^{-1}, \kappa$ is the dimensionless Weibull shape parameter, and $c$ is the Weibull scale parameter having the same units as $v$.

Several different numerical methods have been proposed and compared to estimate the Weibull parameters in previous studies $[56,57]$. The performance of these methods improves with increasing dataset size [56]. Following these studies, different common numerical methods, including the moment, graphical, empirical, energy pattern factor method, maximum likelihood and modified maximum likelihood, are 
tested in determining the parameters of the Weibull distribution, so as to select the most effective method by comparing performance for this study. The methods for estimating Weibull parameters used in this study can be found in previous studies, e.g.,

$4 \quad[56,57]$.
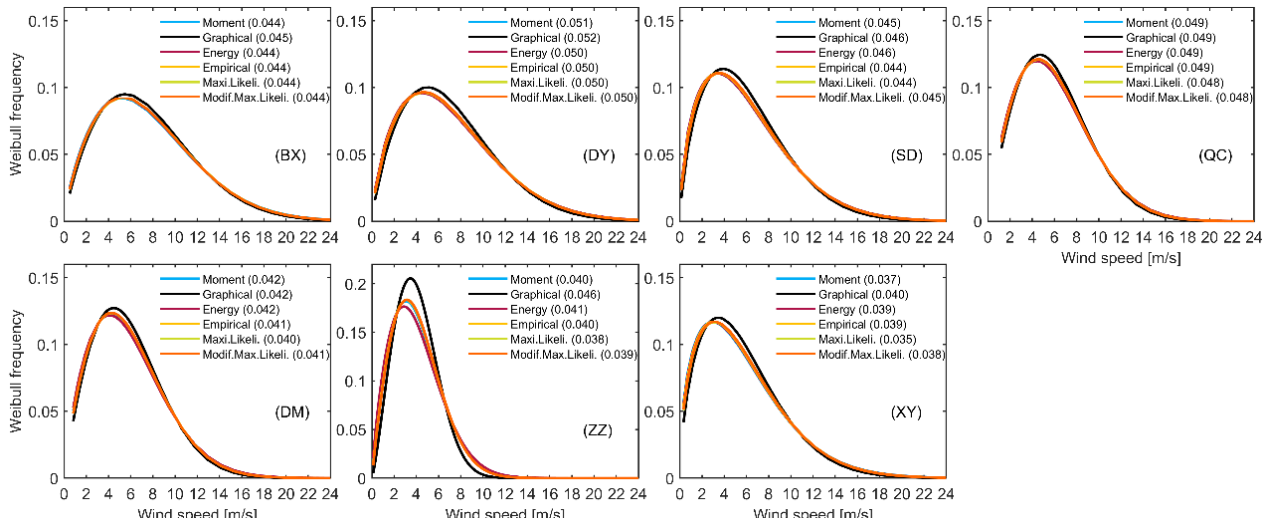

6Figure 3 : Weibull distributions based on the six methods for estimating Weibull parameters (i.e., the 7 moment, graphical, empirical, energy pattern factor method, maximum likelihood and modified 8 maximum likelihood) for the seven sites shown in Figure 1. The values in parentheses represent 9 RMSEs (root mean square errors).

The performance of the methods for estimating Weibull parameters listed above 11 (i.e., the moment, graphical, empirical, energy pattern factor method, maximum 12 likelihood and modified maximum likelihood) are compared to test which are 13 effective for this study. Figure 3 shows the PDFs (probability density functions) for 14 each of the seven sites located in the Beibu Gulf, and calculated from wind data for 15 the period 2010 to 2017 . The difference between the curve calculated using the 16 graphical method and the other methods is most obvious. To further test the accuracy of these methods, the judgment of accuracy of the RMSE (root mean square error) used in [56,57] is adapted for the present study. The RMSE is defined as RMSE = $19\left[\frac{1}{N} \sum_{i=1}^{N}\left(y_{i}-x_{i}\right)^{2}\right]^{\frac{1}{2}}$, where $y_{i}$ is the frequency of observations, $x_{i}$ represents the 20 frequency of Weibull, and $\mathrm{N}$ is the number of observations. The RMSEs of the six methods for the seven sites are listed in the parentheses of Figure 3. It can be seen from these values that the performance of the maximum likelihood method is on 
average best. Therefore, the study uses this method for determining the Weibull parameters for further analyses in the following sections.

\subsection{Most probable wind speed}

The estimated Weibull parameters are directly used so as to obtain most probable wind speeds, thereby indicating most frequent wind speed for a given PDF. The most probable wind speed, $V_{m p}$, is computed in terms of Weibull distribution parameters [29,51]:

$$
V_{m p}=c\left(1-\frac{1}{\kappa}\right)^{\frac{1}{\kappa}}
$$

\subsection{Wind speed carrying maximum energy}

The Weibull parameters are also used to compute wind speed containing maximum energy, $V_{\max . E}$, for a wind turbine, which is also the speed that produces the most energy. $V_{\max . E}$ can also be adapted for estimating wind turbine rated wind speeds, which can be defined as follows [29, 43, 50]:

$$
V_{\max . E}=c\left(1+\frac{2}{\kappa}\right)^{\frac{1}{\kappa}}
$$

\subsection{Wind power density}

Wind power density is an important parameter for evaluating available resources at potential sites. Wind power, measured in $\mathrm{Wm}^{-2}$, per unit swept area of a turbine is proportional to the cube of the wind speed. In terms of Weibull distribution parameters, the wind power per unit area can be defined as follows [29, 50, 60-63]:

$$
P=\frac{1}{2} \rho \int_{0}^{\infty} v^{3} f(v) d v=\frac{1}{2} \rho c^{3} \Gamma(1+3 / \kappa)
$$

where $c$ and $\kappa$ are still the Weibull parameters.

\subsection{Limitations of the analysis of this study}

We wish to state for the record that the analysis of the present study is meant as a first pass only at estimating the viable offshore wind resource in order to highlight the availability of this resource within the study region.

For the study period from August 2009 to December 2017, the valid number of observations from all data records used in the study at each of the stations (i.e., BX, DY, SD, QC, DM, ZZ, XY) was, respectively, about $76 \%, 83 \%, 88 \%, 85 \%, 72 \%$, $99 \%, 77 \%$ (see Table 1). This means that there were data losses of approximately $24 \%$, $17 \%, 12 \%, 15 \%, 28 \%, 1 \%$ and $23 \%$ for each station, respectively, indicating that better and more reliable datasets are needed for the region, especially for stations BX, 
DM and XY. This is a recommendation of the present study for follow-up work.

Moreover, the analysis is also limited by wind turbine hub height and measurement

locations. However, once better datasets become available for the region, further

analysis will be undertaken using the latest offshore wind turbine parameters.

6 4. Wind energy assessment in the Beibu Gulf

To interpret wind climate and potential wind energy characteristics at the stations

8 shown in Figure 1, wind features were analyzed based on detailed observational data,

9 including mean wind speed, prevailing direction, diurnal and monthly variations,

10 together with Weibull distributions, and the wind power density. The observed wind

11 speed data have been converted from anemometer height to wind turbine hub height

12 by use of the power-law approximation introduced in Section 2. Converted data have

13 been used in this study, whereas we assumed wind directions do not vary with height.

14 Moreover, for the present study, the four boreal seasons are winter

15 (December-February), spring (March-May), summer (June-August), and Autumn

16 (September-November). 

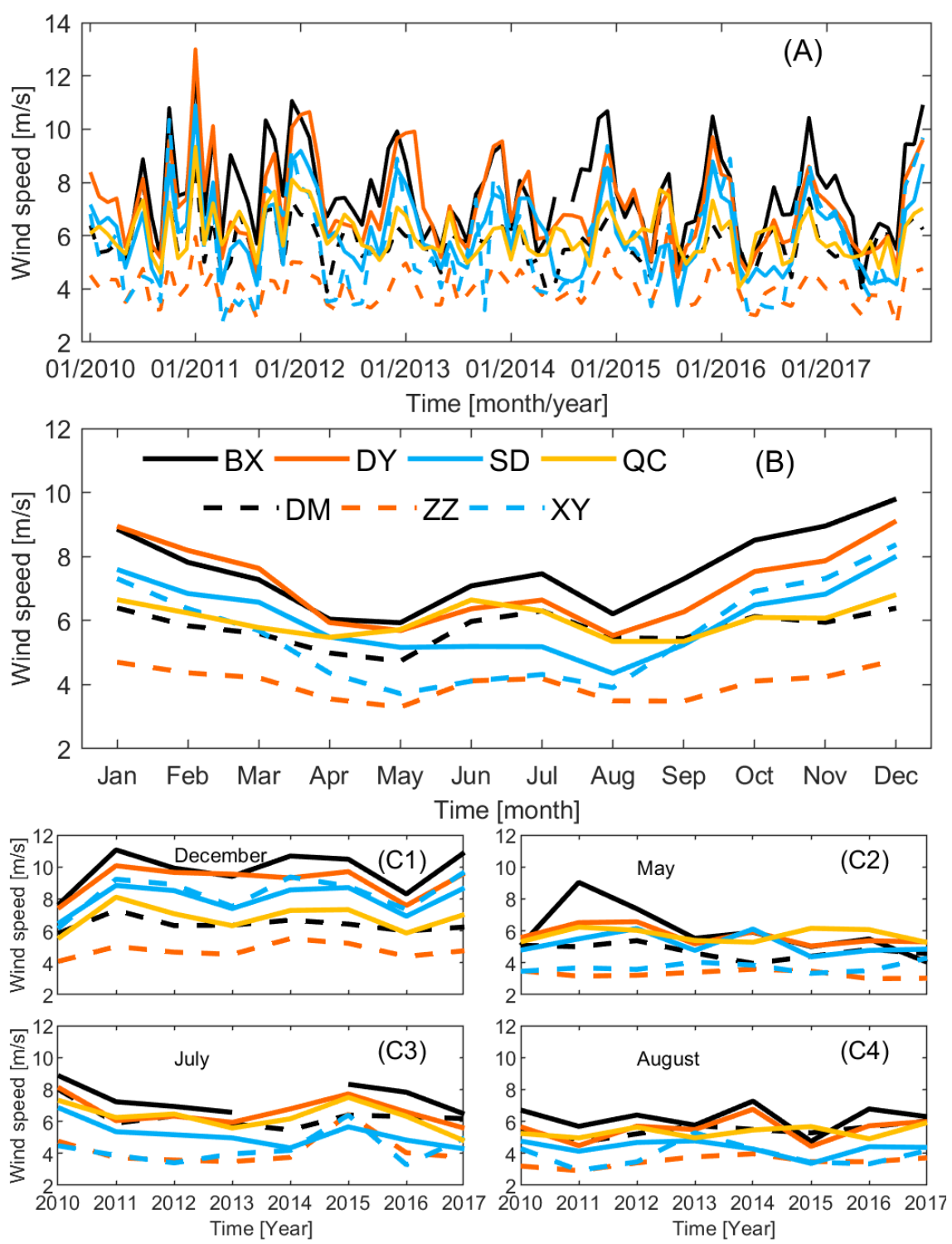

2 Figure 4 : Intra- and inter-annual variability of wind speeds $\left(\mathrm{ms}^{-1}\right)$ over the period 2010 to 2017 for the seven sites shown in Figure 1. (A) Monthly wind speed; (B) Monthly climatology of wind speed; (C1-C4) Year-to-year variability for different month (December, May, July and August) of the wind speed.

\section{$6 \quad 4.1$ Inter- and intra-annual wind speed variations}

$7 \quad$ Monthly mean and seasonal wind speed characteristics were investigated for the

8 study sites, based on observations collected over the period 2010 to 2017 , to show

9 inter- and intra-annual wind speed variability. 
Figure 4(A) illustrates monthly wind speed for the seven sites. Intra- and inter-annual variability is obvious. Monthly wind speed values at the sites ranged

3 from about $3.0 \mathrm{~ms}^{-1}$ to $12.0 \mathrm{~ms}^{-1}$, with annual mean wind speed values varying 4 between $4.0 \mathrm{~ms}^{-1}$ and $7.6 \mathrm{~ms}^{-1}$ (see Table 1), although January 2011 values were 5 relatively higher at all sites, with a highest monthly wind speed value of about 15.6 $6 \mathrm{~ms}^{-1}$ found at DY.

Figure 4(B) shows monthly wind speed climatologies for the seven sites. Intra-annual wind sped variability is evident, with annual climatologies exhibiting two cycles per year: largest wind speeds occurring in December with another peak value in July, and lowest wind speeds apparent in May with another trough in August.

Figure 4(C1-C4) shows year-to-year wind speed variability for months containing peak and trough wind speed values. Inter-annual variability seems weaker than intra-annual variability. In addition, most of the seven sites display quite similar inter-annual variations, especially for December and July.

The long-term trend of the wind speed at the seven sites was also checked, however, no significant trend can be verified for the period of interest. This is because the observational period is relatively short to for determining a conclusion on the long-term trend in wind climate change for the study area, especially when considering response to global climate change.

\subsection{Diurnal wind speed variations}

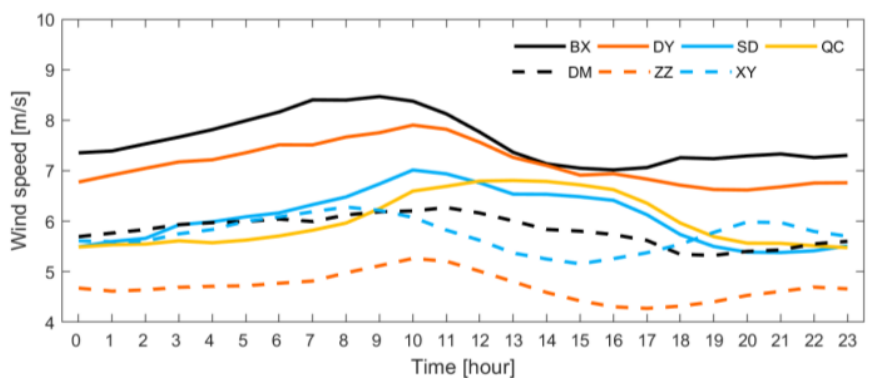

Figure 5 : Diurnal mean wind speed $\left(\mathrm{ms}^{-1}\right)$ for the eight sites shown in Figure 1.

Besides monthly and seasonal probability wind speed distributions, diurnal mean wind speed variations are also analyzed in this study to explain hourly wind speed probabilities, and are presented in Figure 5 for each of the seven sites. A clear feature 
1 at each site is that for sites BX, DY, ZZ and XY, which are the furthest from shore and

2 closer to the open sea, hourly mean wind speed is largest in day time (8:00-18:00);

3 while at SD, QC and DM, closer to the mainland, wind speeds are relatively small in

4 the afternoon.

54 Weibull distribution

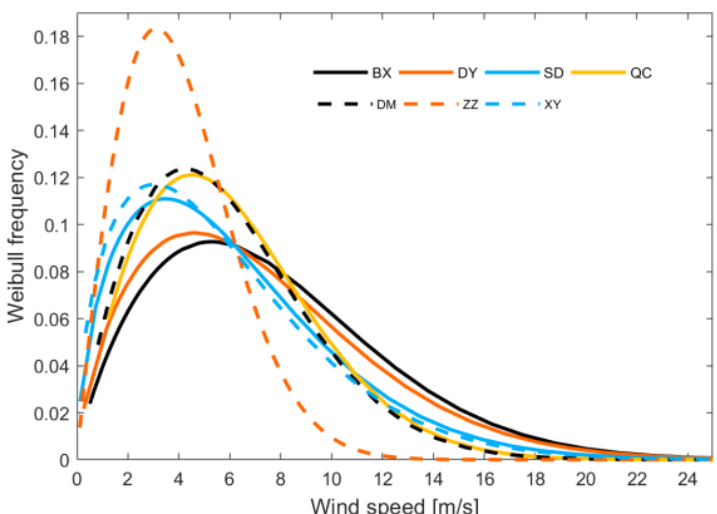

Figure 6 : Annual Weibull probability distributions at all sites for the period 2010 to 2017.

Formatted: Space After: 0.5 line

Annual wind speed Weibull distributions at all sites are highlighted in Figure 6,

9 and annual mean Weibull parameters for period 2010-2017 are listed in Table 1Table

10 1. As seen in Figure 6, the curve peak represents the most frequent wind speed.

11 The shape parameter, $\kappa$, was in the range 1.5-1.9 at all stations, while scale

12 parameter, $c$, varied between $4.6 \mathrm{~ms}^{-1}$ and $8.6 \mathrm{~ms}^{-1}$. The average values of the shape

13 and scale parameters for all sites were, respectively, $1.7 \mathrm{~ms}^{-1}$ and $6.8 \mathrm{~ms}^{-1}$. 

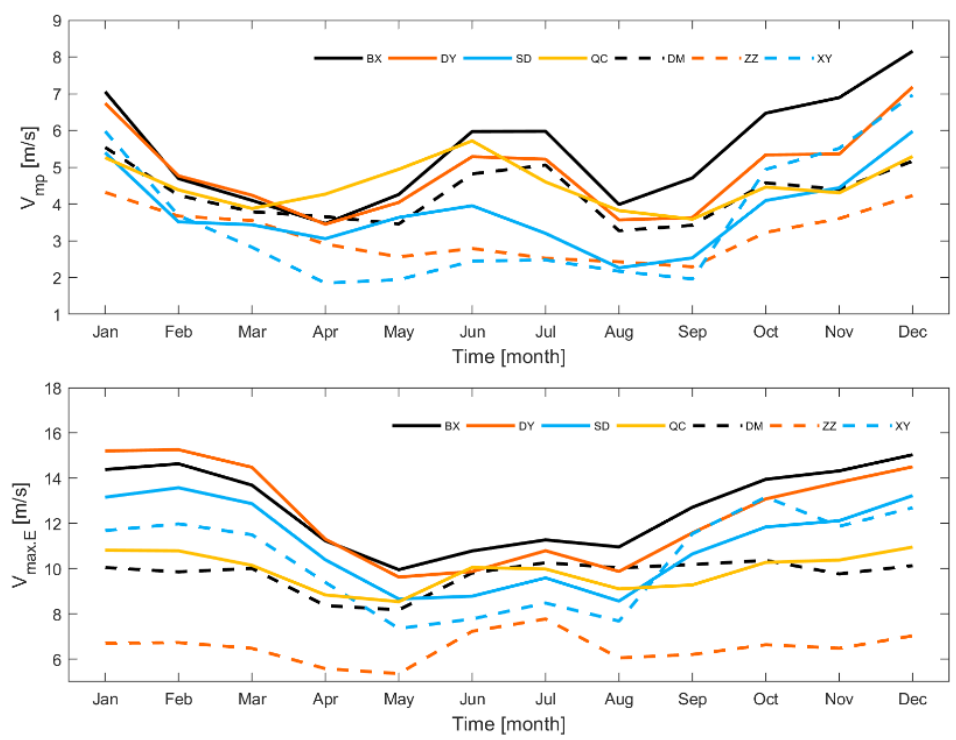

Figure 7 plots the variability in monthly mean values of most probable wind speed, $V_{m p}$, and wind speed containing most energy, $V_{\max . E}$, observed at the seven sites. Concerning $V_{m p}$, monthly values were mostly confined to the range $2-9 \mathrm{~ms}^{-1}$ at all sites. $V_{m p}$ displayed seasonality similar to that of wind speed and Weibull parameters: relatively high values in December and January, low values in April, May and August, with increased values in June and July. Likewise, $V_{\max . E}$ also exhibits

10 obvious seasonal changes. Annual mean values of $V_{m p}$ and $V_{\max . E}$ for the seven 11 sites over the period 2010 to 2017 are also given in Table 1. The largest annual mean 12 values of $V_{m p}$ and $V_{\max . E}$ were found at $\mathrm{BX}$ and DY, with values of $\sim 7.8 \mathrm{~ms}^{-1}$ and $13 \sim 7.1 \mathrm{~ms}^{-1}$, respectively, while a smallest value of $3.9 \mathrm{~ms}^{-1}$ occurred at ZZ.

\subsection{Seasonal wind speed and direction roses}

Beside wind speed, wind direction is another important parameter for assessing of wind energy resources. Seasonal distributions of incoming wind direction and wind speed for the seven sites are presented in terms of a wind rose figure, Figure 8. It is apparent from this figure that seasonal wind direction variability is occurring at the seven locations, mainly reflecting the monsoon characteristics in this region. 
In winter and autumn, northerly to northeasterly offshore winds, i.e. winds from land, prevailed at each of the sites, accounting for greater than $50 \%$ of directional 3 winds, while onshore winds, i.e. winds from the open sea, from S, SW and SE, 4 provided the largest contribution to wind energy resources. In spring, winds from $\mathrm{N}$ to $5 \quad \mathrm{E}$ and to $\mathrm{S}$ accounted for most, mainly reflecting transition season characteristics in 6 wind direction. It is noted, but not surprising, that westerly to northwesterly winds 7 were rare in all seasons at all sites (on average less than 5\%), reflecting South China 8 Sea monsoon characteristics.

Overall, prevailing wind directions in the rim are mainly from opposite N-S

10 directions, which might be good for energy exploitation since focus of wind direction 11 and concentration of energy benefit several types of wind turbines designed to convert 12 wind resources as fully as possible.

13

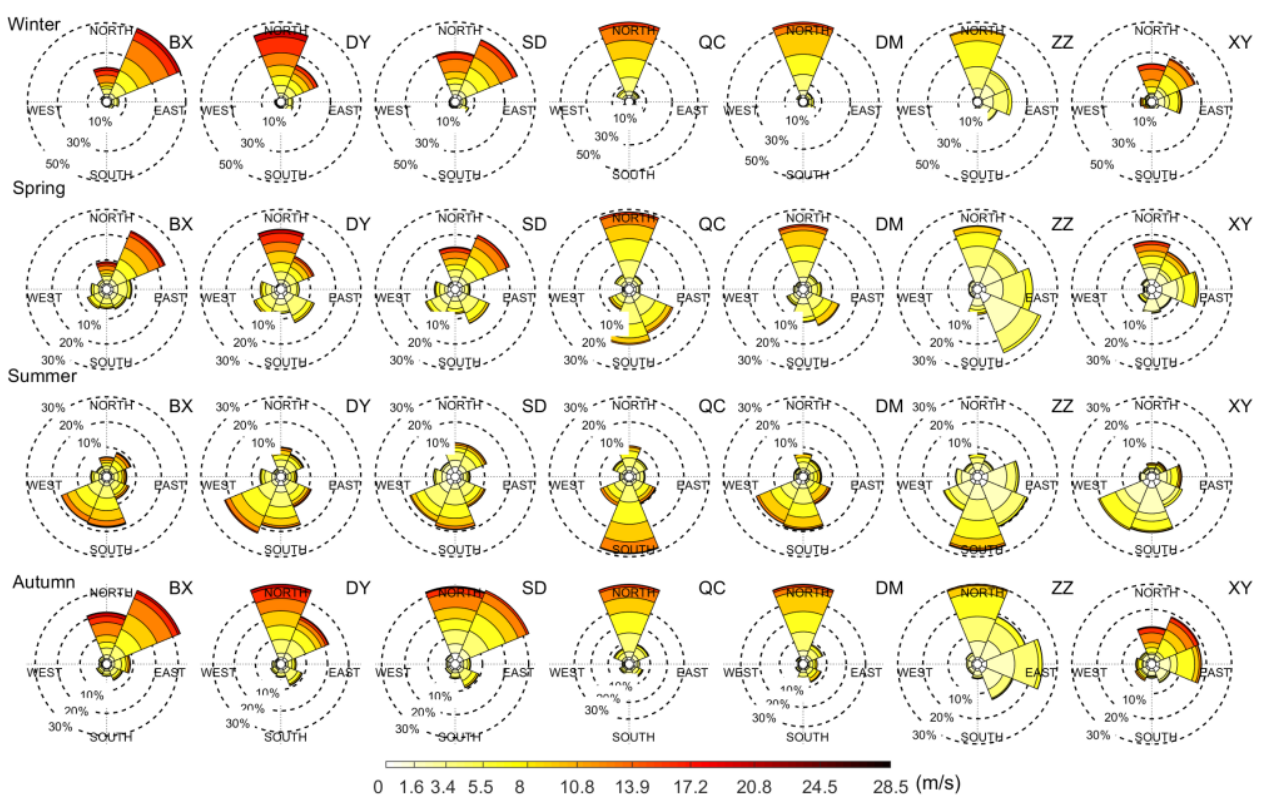
14

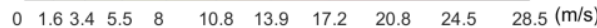

15 Fifgure 8 : Seasonal wind speed and direction roses based on the site measurements for the period 2010 to 2017.

Figure 8 also displays wind speed range percentages at the sites over the period 182010 to 2017. The wind scale is in accordance with the Beaufort scale, as represented 19 by the colors. At BX and DY, wind speeds were mostly from 4 to 9 on the Beaufort 
1 scale, i.e., from $5.5 \mathrm{~ms}^{-1}$ to $24.5 \mathrm{~ms}^{-1}$, reaching 10 on the Beaufort scale in autumn and

2 winter about $5 \%$ of the time. Wind speeds were mostly in the range of 3-8 Beaufort

3 scale at SD and QC, while mostly varied from 3 to 6 on the Beaufort scale at DM and

$4 \mathrm{XY}$, with seasonal changes as mentioned above. Smallest wind speed scales were

5 found at $\mathrm{BH}$ and $\mathrm{ZZ}$ where over $90 \%$ of wind speeds were below 5 Beaufort scale

$6 \quad$ (less than $10.8 \mathrm{~ms}^{-1}$ ).

$7 \quad 4.6$ Wind power density

$8 \quad$ Wind power densities were calculated for the period 2010 to 2017 by use of eq.

33. Wind power density, calculated based on the measurements, are, respectively, 605.6, 542.0, 368.0, 282.0, 265.6, 87.6 and 321.5Wm ${ }^{-2}$ at BX, DY, SD, QC, DM, ZZ and XY stations (see Table 1). It is noted that the Global Wind Atlas (https://globalwindatlas.info/) wind power range for the study region is $200-450 \mathrm{Wm}^{-2}$

13 at $100 \mathrm{~m}$ above MSL. Wind power is higher than the Global Wind Atlas wind power range only at $\mathrm{BX}$ and $\mathrm{DY}$, while mean wind power averaged over the seven stations is $353.2 \mathrm{Wm}^{-2}$, which is within the range of Global Wind Atlas.

Figure 9 describes the intra- and inter-annual variation in terms of monthly mean wind power density for each site. Since wind power density is a function of wind speed only, characteristics of its variability are in good agreement with the corresponding wind speed variations. Intra- and inter-annual variability in wind power patterns display quite similar characteristics at most of the seven sites. Intra-annual variability was evident at all sites: wind power density values were largest in December, while lowest in August; another peak/trough wind speed occurred in July/May. This variability might somehow favour wind energy exploitation and usage: monthly changes in electricity consumption for Guangxi province in the rim is relatively high in summer time, while lowest in February and April (see Figure 2). 

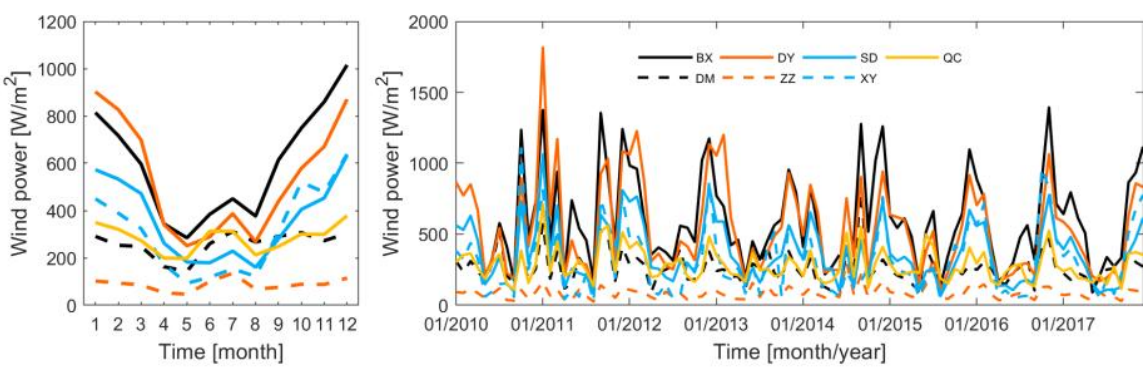

2 Figure 9 : Seasonal (left) and monthly (right) mean wind power density $\left(\mathrm{Wm}^{-2}\right)$ for the sites shown in

Figure 1.

In accordance with mean wind-speed and Weibull parameters, for spatial variation, the annual mean wind power density, $P_{\text {mean }}$ (shown in Table 1), was

greatest at BX with a value of $605.6 \mathrm{Wm}^{-2}$, and least at $\mathrm{ZZ}$ with a value of $87.6 \mathrm{Wm}^{-2}$.

\subsection{Estimation of the potential contribution of coastal wind in the study area}

In 2017 , more than $1.16 \mathrm{GW}$ of additional offshore wind power capacity was installed in Chinese coastal areas, while there has been no installed capacity in the Beibu Gulf up to the end of 2017 [47]. If a turbine with 5 MW capacity is installed in the study area, it would provide about $11 \mathrm{GWh}$ in one year, with annual utilization time of installed capacity in Guangxi being 2280 hours in 2017, based on official data [47]. Thus, a wind farm with 100 such turbines would generate about $1.1 \mathrm{TWh}$ electricity, which can contribute about $0.8 \%$ and $3.6 \%$ of total electricity consumption in 2017 for Guangxi and Hainan provinces, respectively.

\section{Conclusions}

The Beibu Gulf Economic Rim is critical for China's development, and especially for the western China region. The "Beibu Gulf Cities Development Project" sanctioned in 2017 plans to build a "Blue Livable Gulf" to avoid the well-worn routine of priority for economic development, while sacrificing the environment. Electricity consumption data of the rim shows a rising demand in the past ten years and indicates rapid growth in the future, reflecting the huge amount of energy required for developing these cities, with primary consideration given to clean energy. 
In this study, a comprehensive statistical analysis and assessment of wind field and associated energy potential with detailed resource characterization in the study area for the period 2010 to 2017 was conducted at seven offshore coastal sites mention the sites again here. Annual mean wind speed values for the period 2010 to 2017 for the seven sites at $100 \mathrm{~m}$ ranged from $4.0 \mathrm{~ms}^{-1}$ to $7.6 \mathrm{~ms}^{-1}$, resulting in annual mean wind power densities, respectively, of 605.6, 542.0, 368.0, 282.0, 265.6, 87.6 and $321.5 \mathrm{Wm}^{-2}$ at the seven sites (BX, DY, SD, QC, DM, ZZ and XY), with average value of $353.2 \mathrm{Wm}^{-2}$. Intra-annual variability of wind power potential is evident at the seven sites, with the greatest wind power occurring in December and another peak value in July, while lowest wind speed values occur in May with another trough in August. The data also display also shows weak inter-annual variations. However, no significant annual trends were found over the period.

The annual mean Weibull shape parameter, $\kappa$, for period 2010-2017 varied from 1.5 to 1.9 at the sites, while the Weibull scale parameter, $c$, was found to have values between $4.6 \mathrm{~ms}^{-1}$ and $8.6 \mathrm{~ms}^{-1}$. The annual mean $V_{m p}$ and $V_{\max . E}$ for the sites were, respectively, in the range 3.9-7.8 $\mathrm{ms}^{-1}$ and 5.3-9.4 $\mathrm{ms}^{-1}$.

Seasonal variability is evident in wind direction, mainly reflecting monsoon characteristics in the region: in winter and autumn, winds were predominantly from the north, with a considerable northeasterly contribution, while southerly winds prevailed in summer. The prevailing wind direction distribution in the rim is good for energy exploiting and usage. Statistical estimates suggest that a wind farm with 100 turbines each of $5 \mathrm{MW}$ capacity would contribute about $0.8 \%$ and $3.6 \%$ of the total electricity consumption in 2017 for Guangxi and Hainan provinces, respectively.

Overall, this study suggests that China, including the Beibu Gulf, has relatively large resources of offshore wind energy that can reduce its dependency on imported fossil fuels, thus ensuring security of energy supply as well as reduced GHG emissions in the Beibu Gulf Economic Rim, China and the world.

Finally, it should be stated that there was a data loss of more than $20 \%$ in the measurement records at three of the seven stations (i.e., 24\%, 28\% and 23\%, respectively, for stations $\mathrm{BX}, \mathrm{DM}$ and $\mathrm{XY}$ ) used in this study. Estimates of wind 
speed and wind power variability may be influenced by gaps in the data. We wish to state, for the record, that the analysis of the present study is meant as a first pass only at estimating the viable offshore wind resource in order to highlight the rich offshore wind resource available for the study region. Better and more reliable datasets are needed for follow-up work. Once these improved datasets become available for the region, further analysis will be undertaken using the latest offshore wind turbine parameters.

\section{Acknowledgements}

Xinping Chen was funded by the National Natural Science Foundation of China (NSFC) grant 41506042. Aoife Foley was supported by the Northern Ireland "Department for Economics USI 110 US \& Ireland R\&D Research Partnership" under the US-Ireland Research and Development Partnership program Science Foundation Ireland and the United States National Science Foundation Collaborative Research Decentralisation, ElectrificatioN, Communications and Economics (CREDENCE) Centre-to-Centre Award.

\section{Reference}

[1]Perveen R, Kishor N, Mohanty SR. Off-shore wind farm development: Present status and challenges. Renew Sustain Energy Rev 2014;29:780-92.

[2]Rodrigues S, Restrepo C, Kontos E, Teixeira Pinto R, Bauer P. Trends of offshore wind projects. Renew Sustain Energy Rev 2015;49:1114-35.

[3](GWEC) GWEC. Global Wind Energy Outlook | 2016. 2016.

[4]Wind Europe. Wind energy in Europe: Outlook to 2020. Wind Eur 2017;September 2017.

[5](GWEC) GWEC. Global Wind Report Annual Market Update. 2018.

[6]REN21. RENEWABLES 2015: Global Status Report (the Renewable Energy Policy Network for the 21 st Century). 2015.

[7]Esteban MD, Diez JJ, López JS, Negro V. Why offshore wind energy? Renew Energy 2011;36:444-50. 
[8]Bilgili M, Yasar A, Simsek E. Offshore wind power development in Europe and its comparison with

2 onshore counterpart. Renew Sustain Energy Rev 2011;15:905-15.

3 [9]J.Dvorak M, L.Archer C, Z.Jacobson M. California offshore wind energy potential. Renew Energy $4 \quad 2010 ; 35: 1244-54$

5 [10]Dvorak MJ, Corcoran BA, Hoeve JE Ten, Mcintyre NG, Jacobson MZ. US East Coast offshore

6 wind energy resources and their relationship to peak-time electricity demand 2013;16:977-97.

7 [11]Iglesias G, Carballo R. Offshore and inshore wave energy assessment: Asturias (N Spain). Energy

$8 \quad 2010 ; 35: 1964-72$.

9 [12]Colmenar-santos A, Perera-perez J, Borge-diez D. Offshore wind energy : A review of the current 10 status, challenges and future development in Spain. Renew Sustain Energy Rev 2016;64:1-18.

11 [13]Agency EE, EEA. Europe's onshore and offshore wind energy potential. vol. 6. 2009. 12 doi: $10.2800 / 11373$.

13 [14]Shu ZR, Li QS, Chan PW. Investigation of offshore wind energy potential in Hong Kong based on 14 Weibull distribution function. Appl Energy 2015;156:362-73.

15 [15]Langodan S, Viswanadhapalli Y, Dasari HP, Knio O, Hoteit I. A high-resolution assessment of wind and wave energy potentials in the Red Sea. Appl Energy 2016;181:244-55.

17 [16]Cavazzi S, Dutton AG. An Offshore Wind Energy Geographic Information System (OWE-GIS)

18 for assessment of the UK' s offshore wind energy potential. Renew Energy 2016;87:212-28.

19 [17] Sequeira C, Jerez S. An evaluation of offshore wind power production by floatable systems : A 20 case study from SW Portugal 2017;131.

21 [18] Kalogeri C, Galanis G, Spyrou C, Diamantis D, Baladima F, Koukoula M, et al. Assessing the 22 European offshore wind and wave energy resource for combined exploitation. Renew Energy $23 \quad 2017 ; 101: 244-64$.

24 [19]Kim T, Park J-I, Maeng J. Offshore wind farm site selection study around Jeju Island, South Korea. 25 Renew Energy 2016;94:619-28.

26 [20] Oh K-Y, Kim J-Y, Lee J-K, Ryu M-S, Lee J-S. An assessment of wind energy potential at the demonstration offshore wind farm in Korea. Energy 2012;46:555-63.

28 [21]Nagababu G, Kachhwaha SS, Naidu NK, Savsani V. Application of reanalysis data to estimate 29 offshore wind potential in EEZ of India based on marine ecosystem considerations. Energy $30 \quad 2016 ; 118: 622-31$.

31 [22] Gadad S, Deka PC. Offshore wind power resource assessment using Oceansat-2 scatterometer data 32 at a regional scale. Appl Energy 2016;176:157-70. 
[23] Nagababu G, R RS, Naidu NK, Kachhwaha SS. Application of OSCAT satellite data for offshore wind power potential assessment of India. Energy Procedia 2016;90:89-98. [24] Nagababu G, Kachhwaha SS, Savsani V. Estimation of technical and economic potential of offshore wind along the coast of India. Energy 2017;138:79-91.

[25]Bates A, Firestone J. A comparative assessment of proposed offshore wind power demonstration projects in the United States. Energy Res $\ \&$ Soc Sci 2015;10:192-205.

[26] Waewsak J, Landry M, Gagnon Y. Offshore wind power potential of the Gulf of Thailand. Renew Energy 2015;81:609-26.

9 [27]Chancham C, Waewsak J, Gagnon Y. Offshore wind resource assessment and wind power plant 10 optimization in the Gulf of Thailand. Energy 2017;139:706-31.

11 [28]Watts D, Oses N, Pérez R. Assessment of wind energy potential in Chile: A project-based regional 12 wind supply function approach. Renew Energy 2016;96:738-55.

13 [29]Mattar C, Borvarán D. Offshore wind power simulation by using WRF in the central coast of Chile. Renew Energy 2016;94:22-31.

[30] Amirinia G, Ma S, Mazaheri S. Offshore wind resource assessment of Persian Gulf using uncertainty analysis and GIS 2017;113:915-29.

[31]Carvalho D, Rocha A, Gómez-Gesteira M, Silva Santos C. Offshore wind energy resource simulation forced by different reanalyses: Comparison with observed data in the Iberian Peninsula. Appl Energy 2014;134:57-64.

20 [32] Carvalho D, Rocha A, Gómez-Gesteira M, Silva Santos C. Offshore winds and wind energy 21 production estimates derived from ASCAT, OSCAT, numerical weather prediction models and buoys 22 A comparative study for the Iberian Peninsula Atlantic coast. Renew Energy 2017;102:433-44. [33] Soares PMM, Lima DCA, Cardoso RM, Nascimento ML, Semedo A. Western Iberian offshore wind resources: More or less in a global warming climate? Special Report on Emissions Scenarios. Appl Energy 2017;203:72-90.

26 [34]Lima DKS, Leão RPS, dos Santos ACS, de Melo FDC, Couto VM, de Noronha AWT, et al. Estimating the offshore wind resources of the State of Ceará in Brazil. Renew Energy 2015;83:203-21. [35]Rodrigues A, Mendonça F, Trevenzoli A, Helena M, Spyrides C. Complementarity of Brazil 's hydro and offshore wind power. Renew Sustain Energy Rev 2016;56:413-27.

30 [36]Li J, Gao H, Shi P, Shi J, Ma L, Qin H. China wind power report 2007. 2007.

31 [37]Rajgor G. China gets serious on offshore wind. Renew Energy Focus 2010;11:16-9. 
[38]Han J, Mol APJ, Lu Y, Zhang L. Onshore wind power development in China: Challenges behind a

2 successful story. Energy Policy 2009;37:2941-51.

3 [39] Jiang D, Zhuang D, Huang Y, Wang J, Fu J. Evaluating the spatio-temporal variation of China's 4 offshore wind resources based on remotely sensed wind field data. Renew Sustain Energy Rev $5 \quad 2013 ; 24: 142-8$.

6 [40]Zhang D, Zhang X, He J, Chai Q. Offshore wind energy development in China: Current status and 7 future perspective. Renew Sustain Energy Rev 2011;15:4673-84.

8 [41]Zhou W, Yang H, Fang Z. Wind power potential and characteristic analysis of the Pearl River

9 Delta region, China. Renew Energy n.d.;31.

10 [42]Li G. Feasibility of large scale offshore wind power for Hong Kong - A preliminary study. Renew 11 Energy 2000;21:387-402.

12 [43] Lu L, Yang H, Burnett J. Investigation on wind power potential on Hong Kong islands-an 13 analysis of wind power and wind turbine characteristics. Renew Energy 2002;27:1-12.

14 [44]Gao X, Yang H, Lu L. Study on offshore wind power potential and wind farm optimization in 15 Hong Kong. Appl Energy 2014;130:519-31.

16 [45]Chen X, Wang K, Zhang Z, Zeng Y, Zhang Y, Driscoll KO. An assessment of wind and wave 17 climate as potential sources of renewable energy in the nearshore Shenzhen coastal zone of the South 18 China Sea. Energy 2017;134:789-801.

19 [46]Li D, Geyer B, Bisling P. A model-based climatology analysis of wind power resources at 100-m 20 height over the Bohai Sea and the Yellow Sea. Appl Energy 2016;179:575-89. 21 doi:10.1016/j.apenergy.2016.07.010.

22 [47] China Energy Statistical Yearbook. (2008-2017). National Bureau of Statistics of China.

23 [48]China's Action Plan on Prevention and Control of Air Pollution. 2013.

24 [49]Panofsky HA, Dutton JA. Atmospheric turbulence. Models and methods for engineering 25 applications. 1988.

26 [50]Kwon S-D. Uncertainty analysis of wind energy potential assessment. Appl Energy $27 \quad 2010 ; 87: 856-65$.

28 [51]Islam MR, Saidur R, Rahim NA. Assessment of wind energy potentiality at Kudat and Labuan, 29 Malaysia using Weibull distribution function. Energy 2011;36:985-92.

30 [52]Eskin N, Artar H, Tolun S. Wind energy potential of Gokceada Island in Turkey. Renew Sustain 31 Energy Rev 2008;12:839-51. 
[53]Burton T, Sharpe D, Jenkins N, Bossanyi E. Wind energy handbook. 2011.

2 [54]Bentamy A, Croize-Fillon D. Spatial and temporal characteristics of wind and wind power off the 3 coasts of Brittany. Renew Energy 2014;66:670-9.

4 [55]Fyrippis I, Axaopoulos PJ, Panayiotou G. Wind energy potential assessment in Naxos Island,

5 Greece. Appl Energy 2010;87:577-86.

6 [56]Chang, Pau T. Performance comparison of six numerical methods in estimating Weibull 7 parameters for wind energy application. Appl Energy 2011;88:272-82.

8 [57]Costa Rocha PA, de Sousa RC, de Andrade CF, da Silva MEV. Comparison of seven numerical 9 methods for determining Weibull parameters for wind energy generation in the northeast region of 10 Brazil. Appl Energy 2012;89:395-400.

11 [58]Hernández-Escobedo Q, Saldaña-Flores R, Rodríguez-García ER, Manzano-Agugliaro F. Wind 12 energy resource in Northern Mexico. Renew Sustain Energy Rev 2014;32:890-914.

13 [59]Yip CMA, Gunturu UB, Stenchikov GL. Wind resource characterization in the Arabian Peninsula. 14 Appl Energy 2016;164:826-36.

15 [60]Gökçek M, Bayülken A, Bekdemir Ş. Investigation of wind characteristics and wind energy 16 potential in Kirklareli, Turkey. Renew Energy 2007;32:1739-52.

17 [61]Nawri N, Petersen GN, Bjornsson H, Hahmann AN, Jónasson K, Hasager CB, et al. The wind 18 energy potential of Iceland. Renew Energy 2014;69:290-9.

19 [62]Wang B, Huang F, Wu Z, Yang J, Fu X, Kikuchi K. Multi-scale climate variability of the South 20 China Sea monsoon: A review. Dyn Atmos Ocean 2009;47:15-37. 


\title{
An assessment of wind energy potential in the Beibu Gulf considering the
}

\section{energy demands of the Beibu Gulf Economic Rim}

\author{
Xinping Chen ${ }^{\mathrm{a},{ }^{*}}$, Aoife Foley ${ }^{\mathrm{b}}$, Zenghai Zhang ${ }^{\mathrm{c}}$, Kaimin Wang ${ }^{\mathrm{d}}$, Kieran O'Driscoll ${ }^{\mathrm{e}}$ \\ ${ }^{a}$ National Marine Hazard Mitigation Service of State Oceanic Administration, Beijing 100194, China. \\ ${ }^{b}$ School of Mechanical and Aerospace Engineering, Queen's University Belfast, Belfast BT9 5AH, \\ Northern Ireland, UK. \\ ${ }^{c}$ National Meteorological Center of China Meteorological Administration, Beijing 100081, China. \\ ${ }^{d}$ Shenzhen forecasting center, Shenzhen, Guangdong Province, China. \\ ${ }^{e}$ School of Natural and Built Environment, Queen's University Belfast, Belfast BT9 5AH, Northern \\ Ireland, UK.
}

\section{Abstract}

The Beibu Gulf Economic Rim of China is a key economic region in China as demonstrated by the "Beibu Gulf Cities Development Project" (2017) that plans to build a "Blue Livable Gulf" to balance environmental protection while providing sustainable economic development. This region has significant energy needs and is predicted to exhibit rapid growth in the future.

By means of meteorological observations located at seven islands, a comprehensive statistical analysis on wind energy potential in the northern coastal part of the Beibu Gulf is conducted in this study. Specifically, wind speed, Weibull parameters, wind power density, as well as wind directions on various timescales are analyzed. The analysis shows that annual mean wind power density during 2010-2017 at 100m above mean sea level was, respectively, 605.6, 542.0, 368.0, 282.0, 265.6, 87.6 and $321.5 \mathrm{Wm}^{-2}$ at the seven sites, with average value of $353.2 \mathrm{Wm}^{-2}$. Evidently, wind power potential demonstrates intra-annual variability, with greatest values occurring in December, while another peak value is observed in July. Wind speeds are lowest in May with another trough occurring in August. The data also display weak inter annual variability. The prevailing wind directions in the rim are mainly from opposing directions of $\mathrm{N}$ (winter and autumn) and $\mathrm{S}$ (summer). Keywords: Beibu Gulf, Wind energy, Renewable energy, Wind power, Wind climate

\footnotetext{
* Corresponding author.

Email address: xinp.chen@foxmail.com (Xinping Chen)
} 


\section{Introduction}

The use of wind power as an alternative energy source, both on- and off-shore, has increased rapidly over the last 10 years [1-4]. The offshore market is expected to grow at a higher pace than the onshore market, representing about one quarter of the total new wind power installations by 2020 [3]. One significant development in recent years is the spectacular drop in offshore wind power prices, thus making offshore wind power as competitive as fossil fuels and nuclear power [5]. Besides the cost of wind power, renewables like wind can also provide solutions to relieve some key environmental and social challenges, including improving energy security, creating more jobs, reducing public health and air pollution problems, and mitigating against greenhouse gas emissions (GHG) [3, 6].

When comparing development of wind energy sources, offshore sources have been shown to be superior to onshore sources in a number of ways [7, 8]. For example, offshore wind speeds are usually greater and more steady, leading to less turbulence effects than those on land at nearby sites $[9,10]$. A number of studies have assessed offshore wind characteristics and wind power potential, either globally or at specific sites [e.g., 11-35], providing fundamental information for offshore wind power exploitation, for example, spatial and potential variability of wind energy potential display for different offshore regions.

\subsection{The development of wind energy in China}

China possesses and can potentially harness abundant quantities of onshore and offshore wind energy. It has been reported by the Global Wind Energy Council (GWEC) [5] that as the driver of global market growth for most of the last decade, China installed 21.2 GW of onshore wind and 1.8 GW of offshore wind in 2018, representing $45 \%$ and $40 \%$ of global market share respectively. In 2018, the second largest market was the US with $7.6 \mathrm{GW}$ of new onshore installations, followed by Germany (2.4 GW), India (2.2 GW) and Brazil (1.9 GW). For the offshore market in 2018, China took the lead for the first time, followed by the United Kingdom with 1.3 GW. Germany took the third place (0.9 GW) [5]. 
Although China is the world's largest wind power market in both new and 2 cumulative installations, China also has a very large population of about 1.4 billion. In 3 particular, more than half the people in China live in the eastern coastal region, where 4 the economy is relatively developed, thereby leading to a huge energy demand. 5 Therefore, compared with other countries such as the USA, United Kingdom and 6 Germany, new installations in both onshore and offshore wind market is actually 7 much lower on a per capita basis, indicating that China still needs to strive to develop wind energy exploitation, particularly for nearshore and offshore wind energy.

Additionally, China has a very long coastline, approximately $18,000 \mathrm{~km}$ running from the Bohai Sea in the north to the Beibu Gulf in the south, adjacent to a 12-nautical-mile territorial sea with depths mostly less than $100 \mathrm{~m}$. This means that, firstly, offshore wind is a very viable solution located close to the major coastal urban areas of Tianjin, Shanghai, Guangzhou, Shenzhen and so on, with their many millions of citizens. Secondly, wind power resources vary spatially and temporally: wind power densities along the coast of the Chinese Seas regions range from $200 \mathrm{Wm}^{-2}$ to $1000 \mathrm{Wm}^{-2}$ [36-39], which can also be realized from the Global Wind Atlas (https://globalwindatlas.info/). The potential for offshore wind power has been examined for some coastal regions of China. For example, wind power potential was assessed for the Pearl River Delta region [41] and for Hongkong [29, 42-44]; the nearshore wind energy resources off the Shenzhen coast was carefully evaluated [45]; while a model-based climatology analysis was made for wind power resources over the Bohai Sea and the Yellow Sea [46]. Furthermore, previous studies have shown that even in relatively small offshore areas, wind energy potential can display spatial and temporal differences $[35,45]$. Therefore, before selecting a site to build wind power plants, it is an essential and important first step to conduct a precise survey and assessment of wind energy resources around the region, especially for the offshore region where observational data are still rare and good quality information is limited.

The area of interest in this study is off the coast of Guangxi Zhuang Autonomous Region, located in the Beibu Gulf Economic Rim (BGER) of China, located in the South China Sea (see Figure 1). This is one of the least developed regions of China, 
9
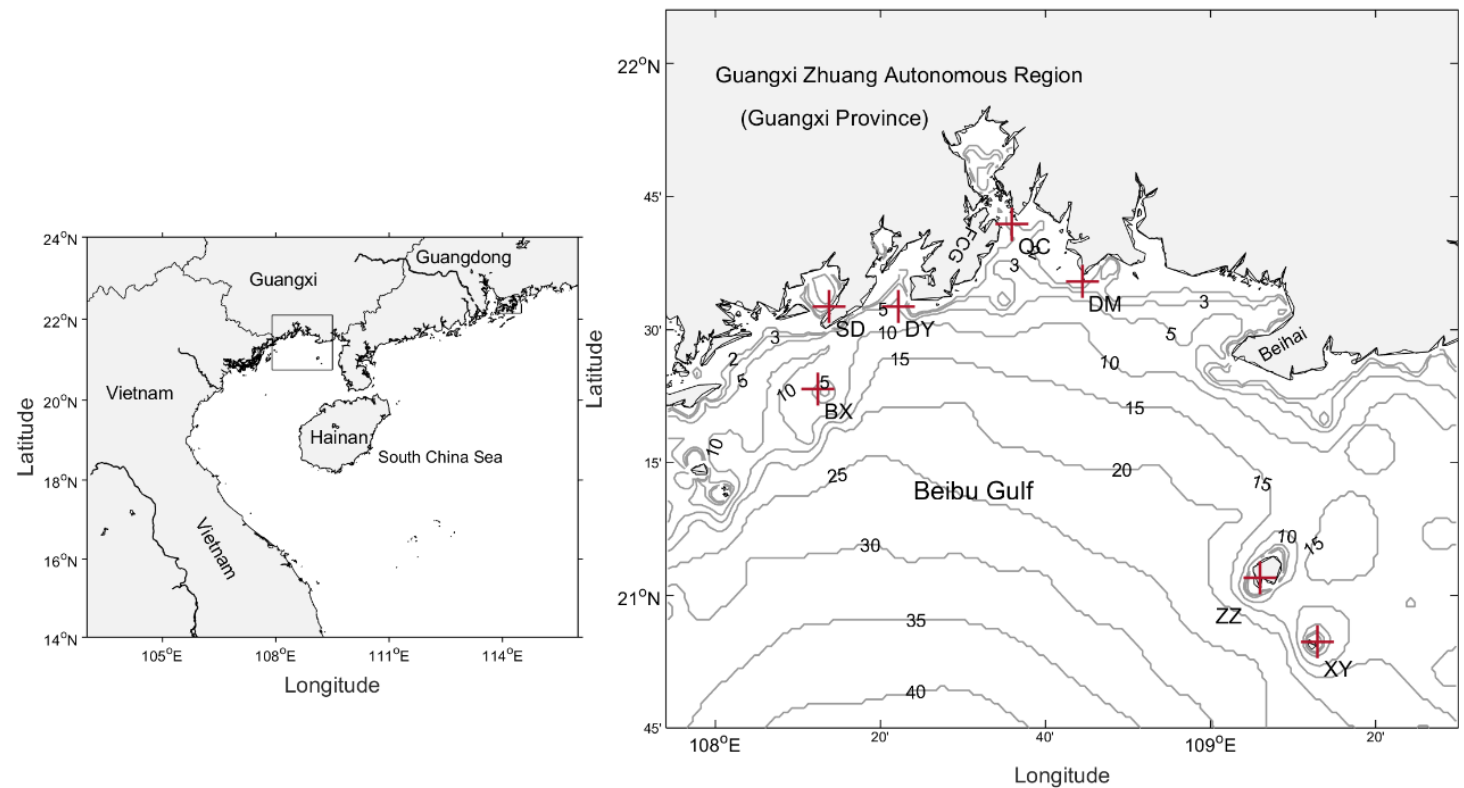

10Figure 1 : Area of the study relative to the northern South China Sea (left) and geographic locations of the 11 seven meteorological sites in red crosses (+ right). 

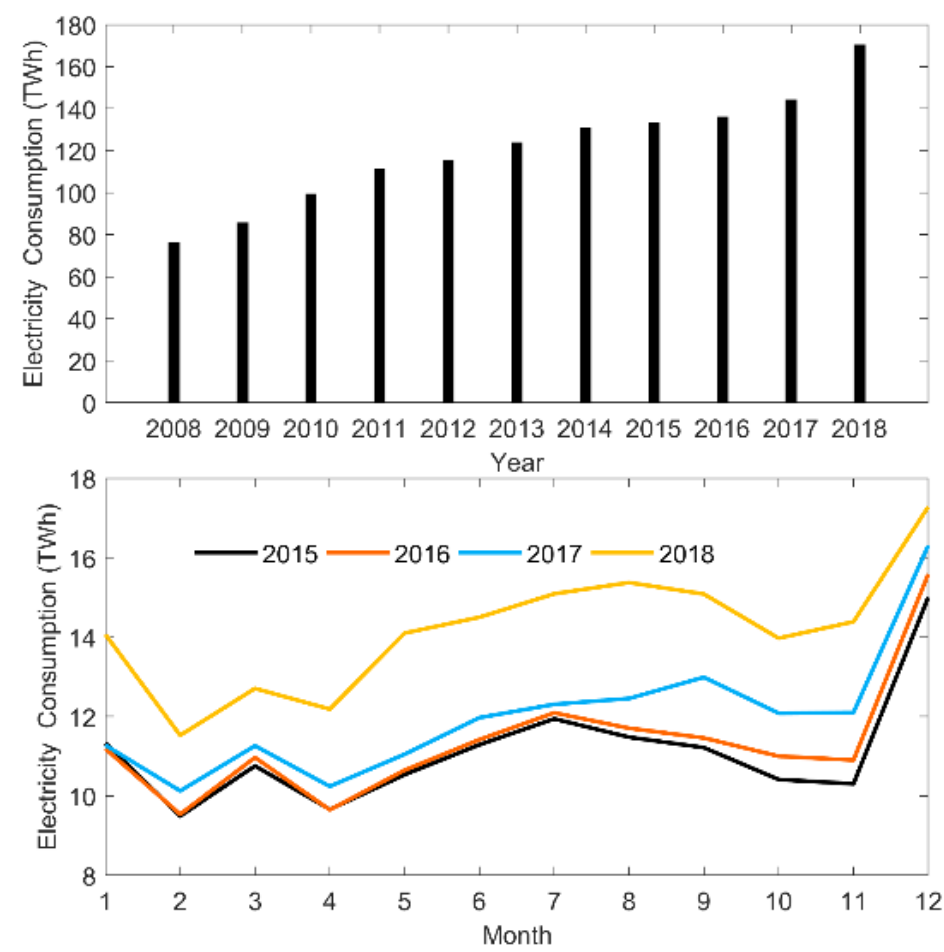

Figure 2: (Top) Electricity consumption of the Guangxi Zhuang Autonomous Region (Guangxi province) for the period 2008-2017; (Bottom) monthly electricity consumption of Guangxi in 2015, 2016 and 2017. (Data resource: China Energy Statistical Yearbook (2008-2017) [47]).

Electricity consumption of Guangxi province in the past 11 years was analyzed to reflect the energy demand for this rim. As shown in Figure 2, the electricity consumption in Guangxi and Hainan provinces has been rising continuously for the past 11 years [47]. Furthermore, since the BGCD project was sanctioned in 2017, the growth rate of the electricity consumption in Guangxi province has risen rapidly, exceeding expectations. In 2018, electricity consumption in Guangxi had reached 170.28TWh, with growth rate up 17.84\% compared with the value of 2017 (144.23 TWh), which is much higher than the growth rate of China $(8.5 \%)$. From the official report, energy consumption in Zhanjiang municipal city in this rim was, $10.80 \mathrm{TWh}$ and 18.15 TWh in 2016 and 2017, respectively, and its year-on-year growth rate was $7.8 \%$ and $18.4 \%$, respectively, with the latter leaping to the top in Guangdong province (Zhanjiang is a municipal city of Guangdong province). Overall, electricity consumption in this rim has rapidly grown, especially from 2017, reflecting the rapid growth of energy demand in the rim. 
3 Development in Eastern China has followed the well-worn global routine of priority

4 for economic growth and expansion, inevitably resulting in air pollution, thus

5 sacrificing the environment without consideration of necessary steps to address the

6 resultant environmental and pollution problems. This approach has resulted in many

7 painful lessons for China, generating serious dialogue and deep thought, thereby

8 compelling China to express its resolute determination to avoid further pollution in

9 less developed regions such as the western region of China. China is now

10 implementing a sustained developmental strategy to accelerate the change of energy structure, particularly with a view to increasing the share of clean sources in its energy mix [48].

The BGER is one such new region to be developed in China, and has been endowed to construct and provide non-polluting industry and tourism. For example, Hainan Island (province), an important part of the BGER, recently officially published the "Implementation plan of National pilot ecological zone (Hainan Province) of China" in May 2019. This initiative clearly points out that Hainan plans to build a "Clean Energy Island", including measures leading to the step by step prohibition of the selling of all petrol vehicles.

At the outset of action formulation and plan development for the BGER, clean green energy, including wind energy, will be the primary consideration. However, wind energy development in this zone has fallen far behind. In 2017, more than 1.16 GW of additional offshore wind power capacity was installed in Chinese coastal areas, while there has been no installed capacity in the Beibu Gulf up to the end of 2017 [47]. Thus, especially because of inadequate knowledge and understanding of coastal wind characteristics, the exploitation of coastal wind energy resources in the region is still lacking.

To assist in the venture of optimal harvesting and utilization of wind power, this paper presents a careful and comprehensive statistical assessment on wind field and energy potential with detailed resource characterization for the period 2010 to 2017, 
1 by means of measurement data collected from seven meteorological stations on

2 coastal islands in the Beibu Gulf. The present study aims to provide insight toward

3 understanding of wind energy potential required in exploring wind energy resources

4 in the study area, in terms of wind speed variation, Weibull parameters and wind

5 power density, as well as wind direction on various timescales. Additionally, to

6 discuss the specific ability of energy development within the region, this study also

7 provides the insight to meet the energy demand for the rim.

\section{Wind data measurement and adjustment}

In this study, data measured at seven meteorological stations on offshore islands and acquired by the CMA, are available for the region. The geographic locations of these seven meteorological stations are given in Figure 1. Before the stations were built, the site selections were fully demonstrated, following related standards and specifications, and data records were carefully checked by the data center of CMA, to ensure that the data are no problem for further analyses. Data collected at the stations are representative of wind climate for different areas of the study region. Data are gathered mainly to monitor atmospheric changes in the region, including forecasting and scrutiny of meteorological and environmental issues, etc. The stations are located at different heights above mean sea level (MSL), while the anemometer for each station is installed at $10 \mathrm{~m}$ height above the surface of each station ground.

In China, each station for surface meteorological measurement must be followed the standard of the "Specifications for surface meteorological observation" (QX/T 45-2007) that published in 2007 (the modified new version is published in 2017 (GB/T 35221-2017)), which specified that surface meteorological stations must be located in the relatively flat and open terrain so as to be representative of relatively large local meteorological characteristics. The stations used in this study meet the standard. The wind monitors at the stations are high performance wind monitor sensors (RM Yong 5106) with blade helicoid propellers, purchased from R.M. Young.

The wind data adapted in the present study include wind speed and direction parameters over the period January 2010 to December 2017. Wind speed parameters 
1 were sampled every $1 \mathrm{~s}$ and averaged over $1 \mathrm{~min}$. Wind direction data was recorded 6

2 times per minute, and also averaged over $1 \mathrm{~min}$. The stations at QC, DM, SD, DY and

$3 \mathrm{BH}$ are located very close to shore, of which QC and DM are located in the mouth of

4 Qingzhou Bay; SD is located in Zhenzhu Bay; DY is located near Fangcheng Port.

$5 \quad \mathrm{BX}$ is further offshore, and $\mathrm{ZZ}$ and $\mathrm{XY}$ are located furthest from shore.

The sensor height at which wind data is measured at the different stations is shown in Table 1. We note the large variability in recorded wind speed, and also that wind speed will vary as a function of recorded height. To extrapolate recorded wind data to likely turbine hub height, hub height is set at $100 \mathrm{~m}$ above MSL for this study, unless otherwise stated. A number of earlier studies have employed mathematical models representing height variability of wind speed, of which the log-law model has been most commonly employed [49]. The simple power-law model is frequently applied to offshore energy applications [14, 49-51], which is also employed in this study. The value 0.13 for the power law exponent has been chosen for this assessment, taken from the previous study of a Korean offshore wind farm, where the farm area is more semi-closed than ocean areas without nearby obstacles and thereby substantially affected by geomorphologic influences [35]. In comparison with the area in this previous study, the geomorphologic condition of the present study area is closer to that of the Korea wind farm.

Table 1 : List of measurement sites in the Guangxi coastal region with some fundamental mean wind and energy characteristics. Hourly collected observational data covered for the period August 2009 to the end of 2017. Table No. of observations represents the valid number of observations used in the study for each station. Total number of the hours over the study period is 70128. Height (m) in the table represents the wind sensor height above the mean sea level at each station. Main wind characteristics were statistically calculated, including wind speed, $V\left(\mathrm{~ms}^{-1}\right)$; Weibull parameters, $\kappa$ and $c\left(\mathrm{~ms}^{-1}\right) ; V_{m p}\left(\mathrm{~ms}^{-1}\right) ; V_{\max . E}\left(\mathrm{~ms}^{-1}\right)$; wind power, $P\left(\mathrm{~W} \mathrm{~m}^{-2}\right)$.

\begin{tabular}{|c|c|c|c|c|c|c|c|}
\hline Site & BX & DY & SD & QC & DM & ZZ & XY \\
\hline No. of observations & 53216 & 57908 & 61610 & 59657 & 50221 & 70001 & 54017 \\
\hline Height & 17.1 & 13.5 & 20.6 & 21.0 & 28.0 & 65.7 & 42.8 \\
\hline $\boldsymbol{V}_{\text {mean }}$ & 7.6 & 7.2 & 6.1 & 6.0 & 5.8 & 4.0 & 5.7 \\
\hline $\boldsymbol{\kappa}$ & 1.8 & 1.7 & 1.6 & 1.9 & 1.8 & 1.9 & 1.5 \\
\hline $\boldsymbol{c}$ & 8.6 & 8.0 & 6.8 & 6.8 & 6.6 & 4.6 & 6.4 \\
\hline
\end{tabular}




\begin{tabular}{|c|c|c|c|c|c|c|c|}
\hline $\boldsymbol{V}_{\boldsymbol{m} \boldsymbol{p}}$ & 7.8 & 7.1 & 5.8 & 6.1 & 5.8 & 3.9 & 5.3 \\
\hline $\boldsymbol{V}_{\text {max. }}$ & 9.4 & 8.8 & 7.7 & 7.6 & 7.3 & 5.3 & 7.3 \\
\hline $\boldsymbol{P}_{\text {mean }}$ & 605.6 & 542.0 & 368.0 & 282.0 & 265.6 & 87.6 & 321.5 \\
\hline
\end{tabular}

\section{Analytical methods}

To provide the statistical analysis of wind characteristics and the assessment of wind energy potential sources associated with wind energy exploitation, several analytical methods are applied and briefly described below.

\subsection{Weibull distribution function}

Probability distribution models are commonly used to fit wind speed distributions over a time period and to obtain a clear view of the available wind potential for a region. A large number of different distribution models have been proposed for statistically analysing both wind characteristics and potential wind as energy assessment. Amongst all the available probability distribution functions, the Weibull probability distribution functions, particularly the two-parameter Weibull function, are commonly used and widely adopted for wind energy applications, not only due to their great flexibility and simplicity but also because they can provide a good representation of recorded wind data [29, 35, 50, 54-57]. Therefore, the two-parameter Weibull distribution model was utilized for the assessment of wind energy potential sources in this study.

The general form of the two-parameter Weibull function can be characterized by the Probability Density Function (PDF), $f(v)\left(f(v)=\left(\frac{k}{c}\right)\left(\frac{v}{c}\right)^{\kappa-1} \exp \left(\left[-\left(\frac{v}{c}\right)^{\kappa}\right]\right)\right)$, and cumulative distribution function, $F(v)$. Here, $v$ is wind speed in $\mathrm{ms}^{-1}, \kappa$ is the dimensionless Weibull shape parameter, and $c$ is the Weibull scale parameter having the same units as $v$.

Several different numerical methods have been proposed and compared to estimate the Weibull parameters in previous studies [56,57]. The performance of these methods improves with increasing dataset size [56]. Following these studies, different common numerical methods, including the moment, graphical, empirical, energy pattern factor method, maximum likelihood and modified maximum likelihood, are 
1 tested in determining the parameters of the Weibull distribution, so as to select the

2 most effective method by comparing performance for this study. The methods for

3 estimating Weibull parameters used in this study can be found in previous studies, e.g.,

$4 \quad[56,57]$.
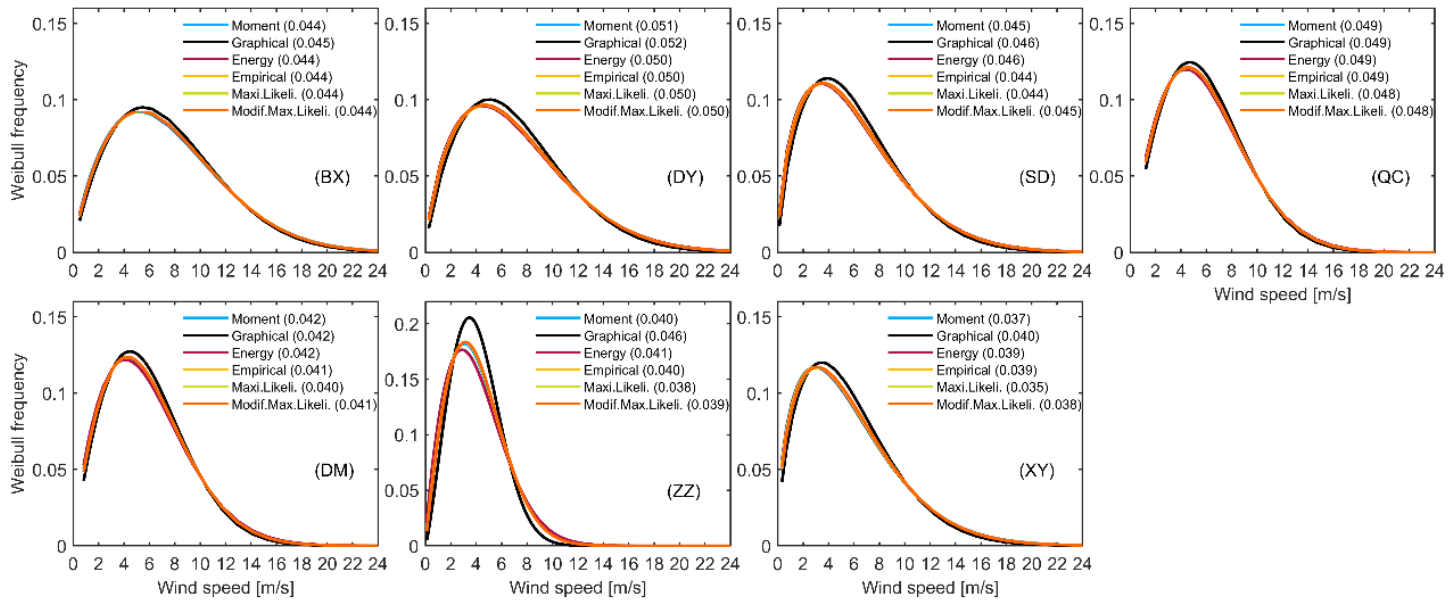

6Figure 3 : Weibull distributions based on the six methods for estimating Weibull parameters (i.e., the

7

8 moment, graphical, empirical, energy pattern factor method, maximum likelihood and modified maximum likelihood) for the seven sites shown in Figure 1. The values in parentheses represent RMSEs (root mean square errors).

The performance of the methods for estimating Weibull parameters listed above (i.e., the moment, graphical, empirical, energy pattern factor method, maximum likelihood and modified maximum likelihood) are compared to test which are effective for this study. Figure 3 shows the PDFs (probability density functions) for each of the seven sites located in the Beibu Gulf, and calculated from wind data for the period 2010 to 2017 . The difference between the curve calculated using the graphical method and the other methods is most obvious. To further test the accuracy of these methods, the judgment of accuracy of the RMSE (root mean square error) used in [56,57] is adapted for the present study. The RMSE is defined as RMSE = $\left[\frac{1}{N} \sum_{i=1}^{N}\left(y_{i}-x_{i}\right)^{2}\right]^{\frac{1}{2}}$, where $y_{i}$ is the frequency of observations, $x_{i}$ represents the frequency of Weibull, and $\mathrm{N}$ is the number of observations. The RMSEs of the six methods for the seven sites are listed in the parentheses of Figure 3. It can be seen from these values that the performance of the maximum likelihood method is on 
1 average best. Therefore, the study uses this method for determining the Weibull

2 parameters for further analyses in the following sections.

$3 \quad 3.2$ Most probable wind speed

The estimated Weibull parameters are directly used so as to obtain most probable wind speeds, thereby indicating most frequent wind speed for a given PDF. The most probable wind speed, $V_{m p}$, is computed in terms of Weibull distribution parameters $[29,51]:$

$$
V_{m p}=c\left(1-\frac{1}{\kappa}\right)^{\frac{1}{\kappa}}
$$

\subsection{Wind speed carrying maximum energy}

The Weibull parameters are also used to compute wind speed containing maximum energy, $V_{\max . E}$, for a wind turbine, which is also the speed that produces the most energy. $V_{\max . E}$ can also be adapted for estimating wind turbine rated wind speeds, which can be defined as follows [29, 43, 50]:

$$
V_{\max . E}=c\left(1+\frac{2}{\kappa}\right)^{\frac{1}{\kappa}}
$$

\subsection{Wind power density}

Wind power density is an important parameter for evaluating available resources at potential sites. Wind power, measured in $\mathrm{Wm}^{-2}$, per unit swept area of a turbine is proportional to the cube of the wind speed. In terms of Weibull distribution parameters, the wind power per unit area can be defined as follows [29, 50, 60-63]:

$$
P=\frac{1}{2} \rho \int_{0}^{\infty} v^{3} f(v) d v=\frac{1}{2} \rho c^{3} \Gamma(1+3 / \kappa)
$$

where $c$ and $\kappa$ are still the Weibull parameters.

\subsection{Limitations of the analysis of this study}

We wish to state for the record that the analysis of the present study is meant as a first pass only at estimating the viable offshore wind resource in order to highlight the availability of this resource within the study region.

For the study period from August 2009 to December 2017, the valid number of observations from all data records used in the study at each of the stations (i.e., BX, DY, SD, QC, DM, ZZ, XY) was, respectively, about 76\%, 83\%, 88\%, 85\%, 72\%, $99 \%, 77 \%$ (see Table 1). This means that there were data losses of approximately $24 \%$, $17 \%, 12 \%, 15 \%, 28 \%, 1 \%$ and $23 \%$ for each station, respectively, indicating that better and more reliable datasets are needed for the region, especially for stations BX, 
DM and XY. This is a recommendation of the present study for follow-up work.

2 Moreover, the analysis is also limited by wind turbine hub height and measurement

3 locations. However, once better datasets become available for the region, further

4 analysis will be undertaken using the latest offshore wind turbine parameters.

\section{4. Wind energy assessment in the Beibu Gulf}

6 To interpret wind climate and potential wind energy characteristics at the stations

7 shown in Figure 1, wind features were analyzed based on detailed observational data,

8 including mean wind speed, prevailing direction, diurnal and monthly variations,

9 together with Weibull distributions, and the wind power density. The observed wind

10 speed data have been converted from anemometer height to wind turbine hub height

11 by use of the power-law approximation introduced in Section 2. Converted data have

12 been used in this study, whereas we assumed wind directions do not vary with height.

13 Moreover, for the present study, the four boreal seasons are winter

14 (December-February), spring (March-May), summer (June-August), and Autumn 15 (September-November). 


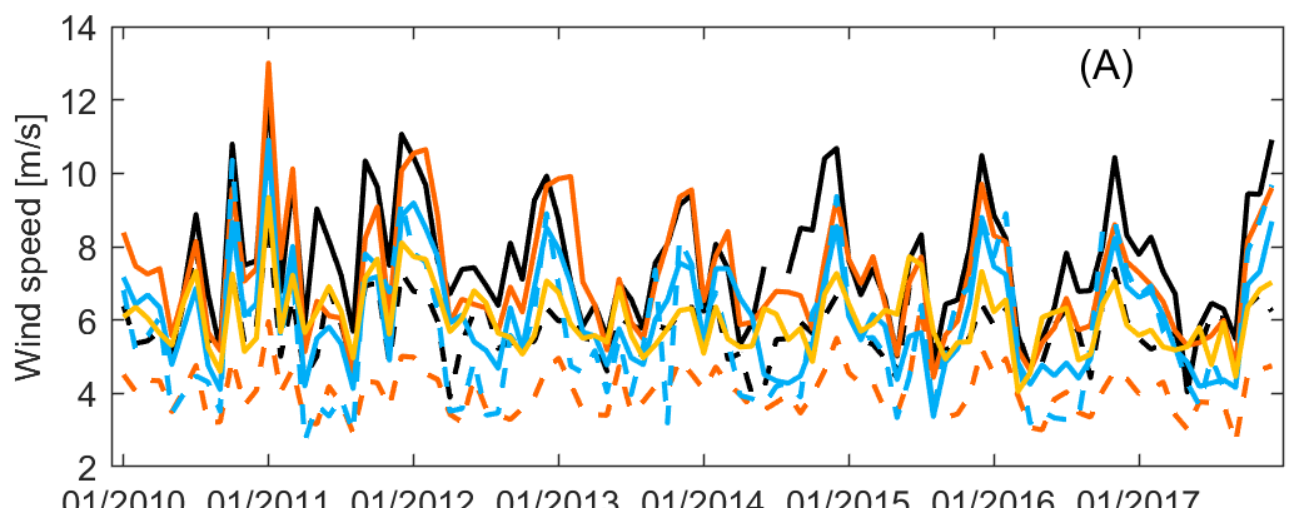

01/2010 01/2011 01/2012 01/2013 01/2014 01/2015 01/2016 01/2017

Time [month/year]

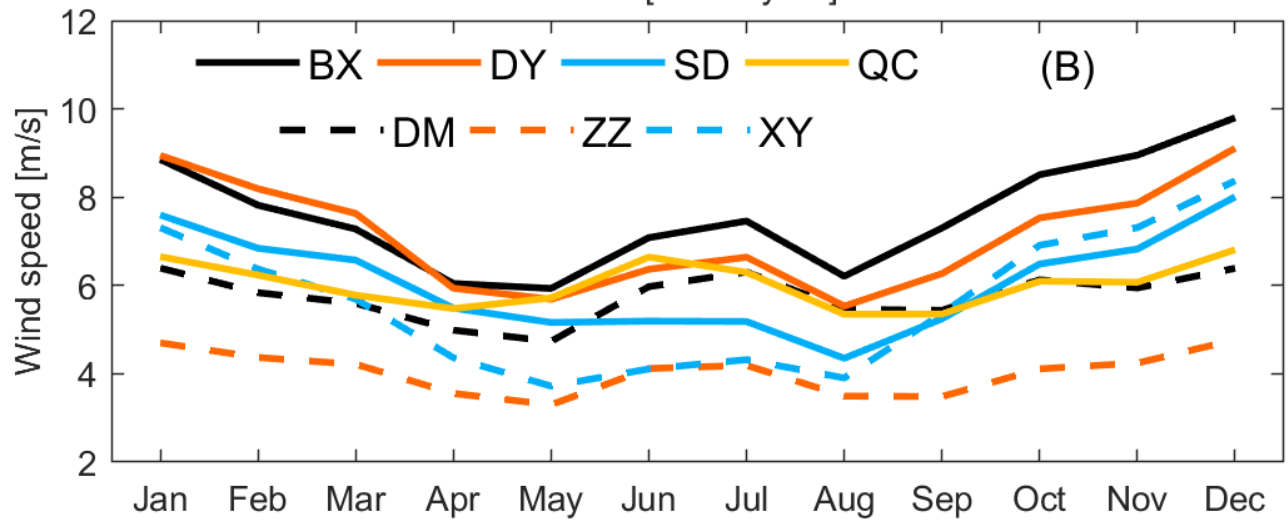

Time [month]
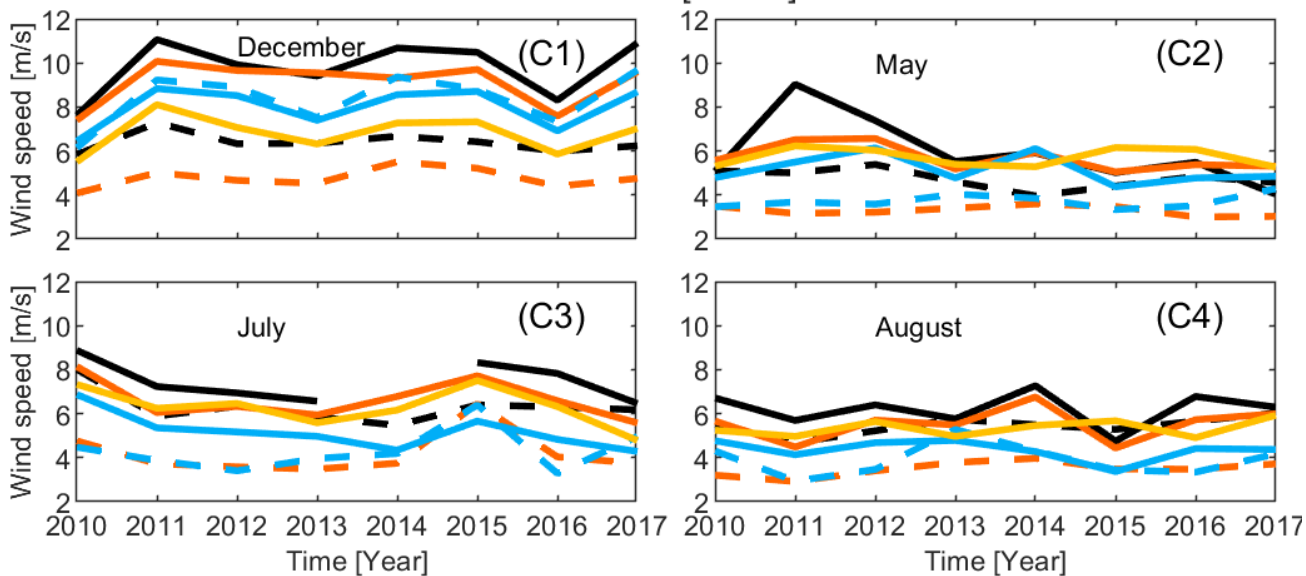

2 Figure 4 : Intra- and inter-annual variability of wind speeds $\left(\mathrm{ms}^{-1}\right)$ over the period 2010 to 2017 for the seven sites shown in Figure 1. (A) Monthly wind speed; (B) Monthly climatology of wind speed; (C1-C4) Year-to-year variability for different month (December, May, July and August) of the wind speed.

\subsection{Inter-and intra-annual wind speed variations}

Monthly mean and seasonal wind speed characteristics were investigated for the

8 study sites, based on observations collected over the period 2010 to 2017, to show

9 inter- and intra-annual wind speed variability. 
Figure 4(A) illustrates monthly wind speed for the seven sites. Intra- and 2 inter-annual variability is obvious. Monthly wind speed values at the sites ranged 3 from about $3.0 \mathrm{~ms}^{-1}$ to $12.0 \mathrm{~ms}^{-1}$, with annual mean wind speed values varying 4 between $4.0 \mathrm{~ms}^{-1}$ and $7.6 \mathrm{~ms}^{-1}$ (see Table 1), although January 2011 values were relatively higher at all sites, with a highest monthly wind speed value of about 15.6 $\mathrm{ms}^{-1}$ found at DY.

Figure 4(B) shows monthly wind speed climatologies for the seven sites. Intra-annual wind sped variability is evident, with annual climatologies exhibiting two cycles per year: largest wind speeds occurring in December with another peak value in July, and lowest wind speeds apparent in May with another trough in August.

Figure 4(C1-C4) shows year-to-year wind speed variability for months containing peak and trough wind speed values. Inter-annual variability seems weaker than intra-annual variability. In addition, most of the seven sites display quite similar inter-annual variations, especially for December and July.

The long-term trend of the wind speed at the seven sites was also checked, however, no significant trend can be verified for the period of interest. This is because the observational period is relatively short to for determining a conclusion on the long-term trend in wind climate change for the study area, especially when considering response to global climate change.

\subsection{Diurnal wind speed variations}

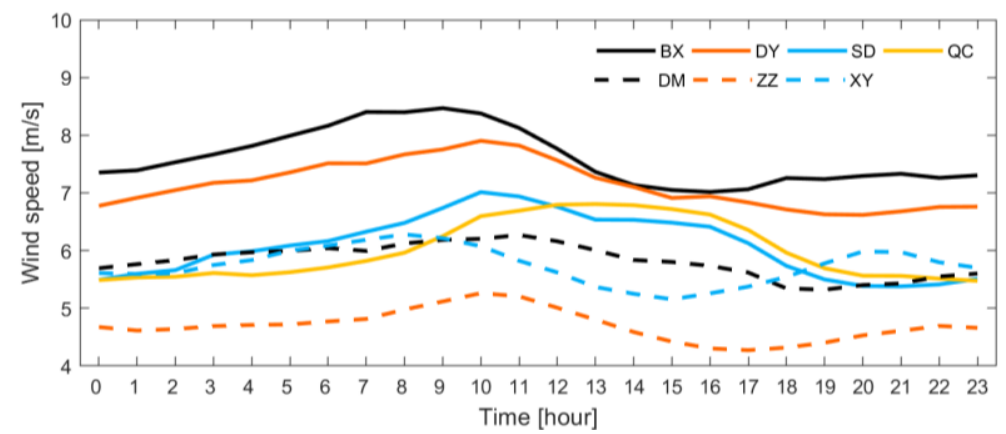

Figure 5 : Diurnal mean wind speed $\left(\mathrm{ms}^{-1}\right)$ for the eight sites shown in Figure 1.

Besides monthly and seasonal probability wind speed distributions, diurnal mean wind speed variations are also analyzed in this study to explain hourly wind speed probabilities, and are presented in Figure 5 for each of the seven sites. A clear feature 
at each site is that for sites BX, DY, ZZ and XY, which are the furthest from shore and

2 closer to the open sea, hourly mean wind speed is largest in day time (8:00-18:00);

3 while at SD, QC and DM, closer to the mainland, wind speeds are relatively small in

4 the afternoon.

54.3 Weibull distribution

(1)

Figure 6 : Annual Weibull probability distributions at all sites for the period 2010 to 2017.

Annual wind speed Weibull distributions at all sites are highlighted in Figure 6, and annual mean Weibull parameters for period 2010-2017 are listed in Table 1Table 1. As seen in Figure 6, the curve peak represents the most frequent wind speed.

1 The shape parameter, $\kappa$, was in the range 1.5-1.9 at all stations, while scale 2 parameter, $c$, varied between $4.6 \mathrm{~ms}^{-1}$ and $8.6 \mathrm{~ms}^{-1}$. The average values of the shape 3 and scale parameters for all sites were, respectively, $1.7 \mathrm{~ms}^{-1}$ and $6.8 \mathrm{~ms}^{-1}$. 


\subsection{Variations of $\boldsymbol{V}_{\boldsymbol{m} \boldsymbol{p}}$ and $\boldsymbol{V}_{\text {max.E }}$}
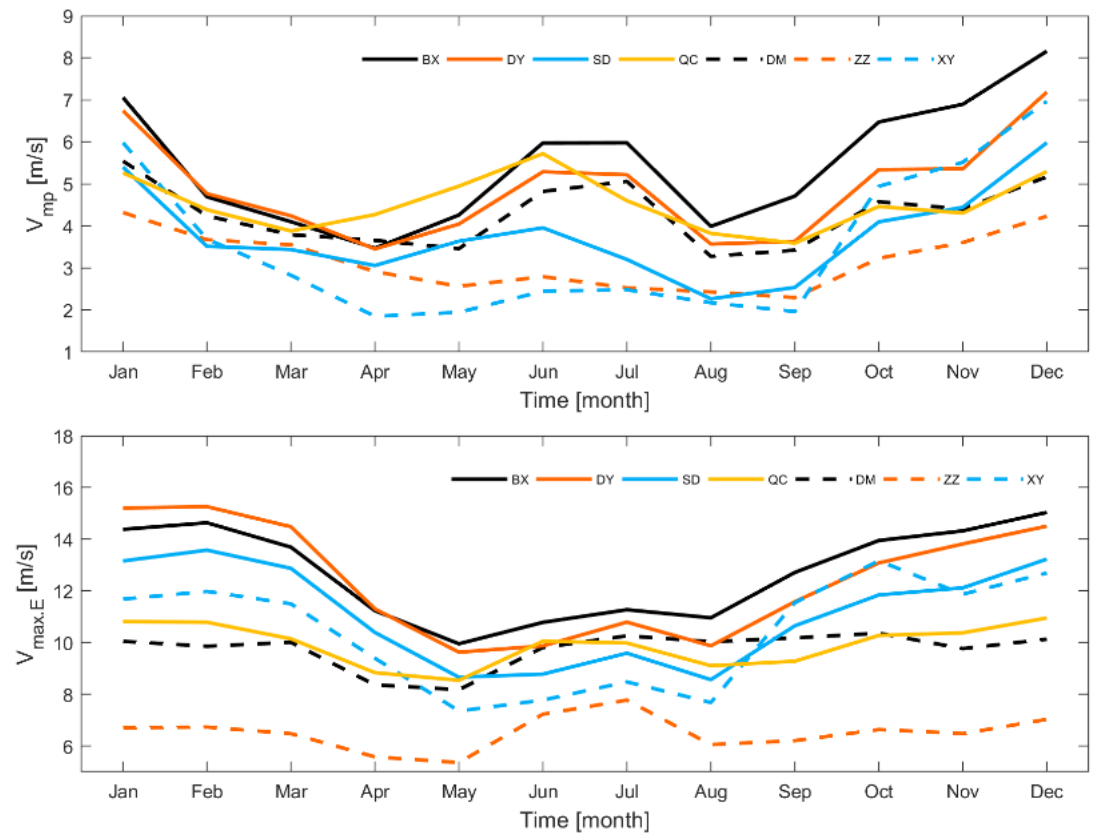

Figure 7 : Monthly variation of $V_{m p}$ and $V_{\max . E}$ at all sites for the period 2010 to 2017.

Figure 7 plots the variability in monthly mean values of most probable wind speed, $V_{m p}$, and wind speed containing most energy, $V_{\max . E}$, observed at the seven sites. Concerning $V_{m p}$, monthly values were mostly confined to the range $2-9 \mathrm{~ms}^{-1}$ at all sites. $V_{m p}$ displayed seasonality similar to that of wind speed and Weibull parameters: relatively high values in December and January, low values in April, May and August, with increased values in June and July. Likewise, $V_{\max . E}$ also exhibits obvious seasonal changes. Annual mean values of $V_{m p}$ and $V_{\max . E}$ for the seven sites over the period 2010 to 2017 are also given in Table 1. The largest annual mean values of $V_{m p}$ and $V_{\text {max.E }}$ were found at BX and DY, with values of $\sim 7.8 \mathrm{~ms}^{-1}$ and $\sim 7.1 \mathrm{~ms}^{-1}$, respectively, while a smallest value of $3.9 \mathrm{~ms}^{-1}$ occurred at ZZ.

\subsection{Seasonal wind speed and direction roses}

Beside wind speed, wind direction is another important parameter for assessing of wind energy resources. Seasonal distributions of incoming wind direction and wind speed for the seven sites are presented in terms of a wind rose figure, Figure 8. It is apparent from this figure that seasonal wind direction variability is occurring at the seven locations, mainly reflecting the monsoon characteristics in this region. 
In winter and autumn, northerly to northeasterly offshore winds, i.e. winds from

2 land, prevailed at each of the sites, accounting for greater than $50 \%$ of directional

3 winds, while onshore winds, i.e. winds from the open sea, from S, SW and SE,

4 provided the largest contribution to wind energy resources. In spring, winds from $\mathrm{N}$ to

$5 \quad \mathrm{E}$ and to $\mathrm{S}$ accounted for most, mainly reflecting transition season characteristics in

6 wind direction. It is noted, but not surprising, that westerly to northwesterly winds

7 were rare in all seasons at all sites (on average less than 5\%), reflecting South China

8 Sea monsoon characteristics.

9 Overall, prevailing wind directions in the rim are mainly from opposite N-S

10 directions, which might be good for energy exploitation since focus of wind direction

11 and concentration of energy benefit several types of wind turbines designed to convert

12 wind resources as fully as possible.

13
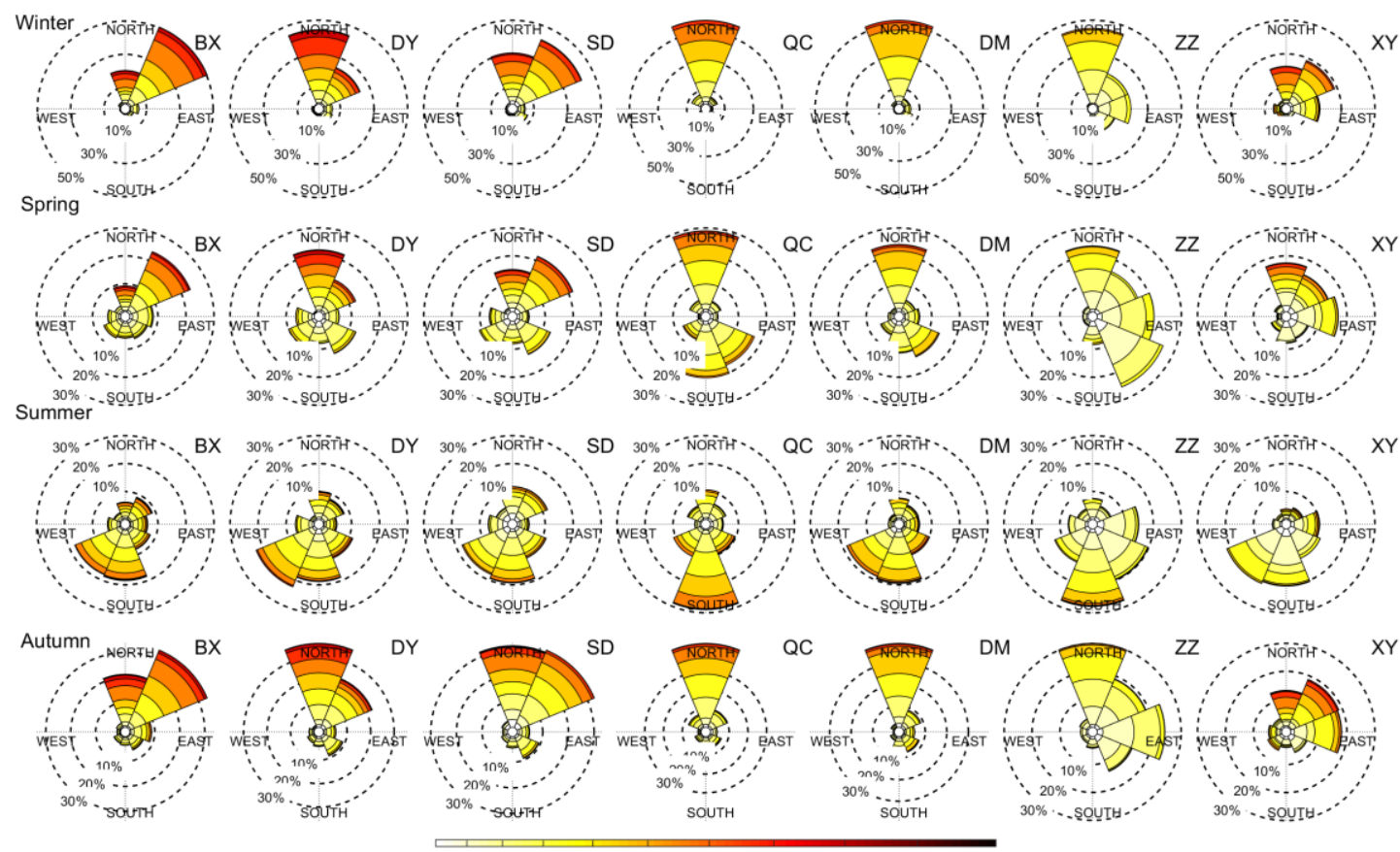

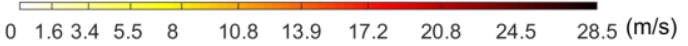

15 Figure 8 : Seasonal wind speed and direction roses based on the site measurements for the period 2010 to 2017.

Figure 8 also displays wind speed range percentages at the sites over the period 2010 to 2017. The wind scale is in accordance with the Beaufort scale, as represented by the colors. At BX and DY, wind speeds were mostly from 4 to 9 on the Beaufort 
1 scale, i.e., from $5.5 \mathrm{~ms}^{-1}$ to $24.5 \mathrm{~ms}^{-1}$, reaching 10 on the Beaufort scale in autumn and

2 winter about $5 \%$ of the time. Wind speeds were mostly in the range of 3-8 Beaufort

3 scale at SD and QC, while mostly varied from 3 to 6 on the Beaufort scale at DM and

$4 \mathrm{XY}$, with seasonal changes as mentioned above. Smallest wind speed scales were

5 found at $\mathrm{BH}$ and $\mathrm{ZZ}$ where over $90 \%$ of wind speeds were below 5 Beaufort scale

6 (less than $10.8 \mathrm{~ms}^{-1}$ ).

\subsection{Wind power density}

Wind power densities were calculated for the period 2010 to 2017 by use of eq. 3 . Wind power density, calculated based on the measurements, are, respectively, 605.6, 542.0, 368.0, 282.0, 265.6, 87.6 and 321.5 $\mathrm{Wm}^{-2}$ at BX, DY, SD, QC, DM, ZZ and XY stations (see Table 1). It is noted that the Global Wind Atlas (https://globalwindatlas.info/) wind power range for the study region is $200-450 \mathrm{Wm}^{-2}$ at $100 \mathrm{~m}$ above MSL. Wind power is higher than the Global Wind Atlas wind power range only at BX and DY, while mean wind power averaged over the seven stations is $353.2 \mathrm{Wm}^{-2}$, which is within the range of Global Wind Atlas.

Figure 9 describes the intra- and inter-annual variation in terms of monthly mean wind power density for each site. Since wind power density is a function of wind speed only, characteristics of its variability are in good agreement with the corresponding wind speed variations. Intra- and inter-annual variability in wind power patterns display quite similar characteristics at most of the seven sites. Intra-annual variability was evident at all sites: wind power density values were largest in December, while lowest in August; another peak/trough wind speed occurred in July/May. This variability might somehow favour wind energy exploitation and usage: monthly changes in electricity consumption for Guangxi province in the rim is relatively high in summer time, while lowest in February and April (see Figure 2). 

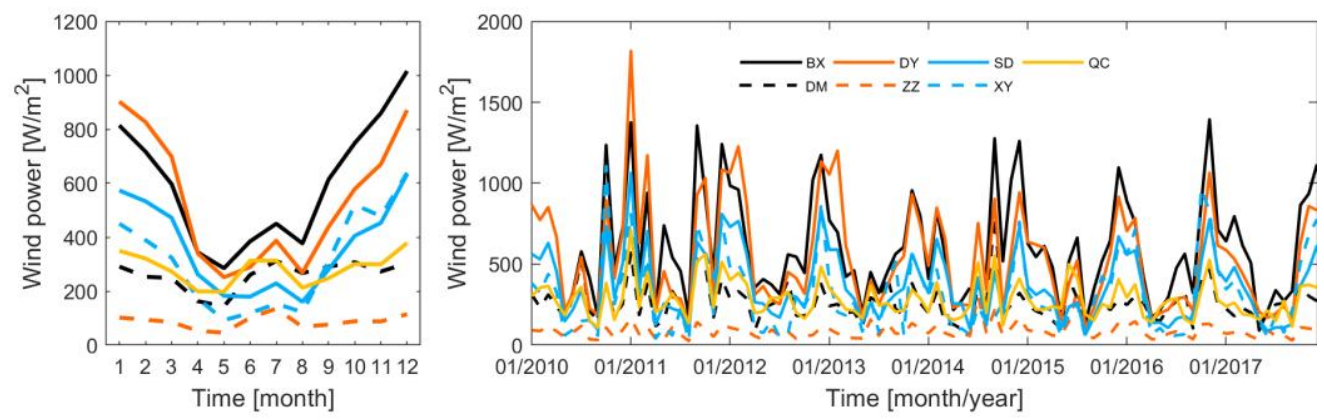

2 Figure 9 : Seasonal (left) and monthly (right) mean wind power density $\left(\mathrm{Wm}^{-2}\right)$ for the sites shown in

3

Figure 1.

In accordance with mean wind-speed and Weibull parameters, for spatial variation, the annual mean wind power density, $P_{\text {mean }}$ (shown in Table 1), was greatest at $\mathrm{BX}$ with a value of $605.6 \mathrm{Wm}^{-2}$, and least at $\mathrm{ZZ}$ with a value of $87.6 \mathrm{Wm}^{-2}$. 4.7 Estimation of the potential contribution of coastal wind in the study area

In 2017 , more than $1.16 \mathrm{GW}$ of additional offshore wind power capacity was installed in Chinese coastal areas, while there has been no installed capacity in the Beibu Gulf up to the end of 2017 [47]. If a turbine with 5 MW capacity is installed in the study area, it would provide about $11 \mathrm{GWh}$ in one year, with annual utilization time of installed capacity in Guangxi being 2280 hours in 2017, based on official data [47]. Thus, a wind farm with 100 such turbines would generate about $1.1 \mathrm{TWh}$ electricity, which can contribute about $0.8 \%$ and $3.6 \%$ of total electricity consumption in 2017 for Guangxi and Hainan provinces, respectively.

\section{Conclusions}

The Beibu Gulf Economic Rim is critical for China's development, and especially for the western China region. The "Beibu Gulf Cities Development Project" sanctioned in 2017 plans to build a "Blue Livable Gulf" to avoid the well-worn routine of priority for economic development, while sacrificing the environment. Electricity consumption data of the rim shows a rising demand in the past ten years and indicates rapid growth in the future, reflecting the huge amount of energy required for developing these cities, with primary consideration given to clean energy. 
In this study, a comprehensive statistical analysis and assessment of wind field 2 and associated energy potential with detailed resource characterization in the study area for the period 2010 to 2017 was conducted at seven offshore coastal sites mention the sites again here. Annual mean wind speed values for the period 2010 to 2017 for the seven sites at $100 \mathrm{~m}$ ranged from $4.0 \mathrm{~ms}^{-1}$ to $7.6 \mathrm{~ms}^{-1}$, resulting in annual mean wind power densities, respectively, of 605.6, 542.0, 368.0, 282.0, 265.6, 87.6 and $321.5 \mathrm{Wm}^{-2}$ at the seven sites (BX, DY, SD, QC, DM, ZZ and XY), with average value of $353.2 \mathrm{Wm}^{-2}$. Intra-annual variability of wind power potential is evident at the seven sites, with the greatest wind power occurring in December and another peak value in July, while lowest wind speed values occur in May with another trough in August. The data also display also shows weak inter-annual variations. However, no significant annual trends were found over the period.

The annual mean Weibull shape parameter, $\kappa$, for period 2010-2017 varied from 1.5 to 1.9 at the sites, while the Weibull scale parameter, $c$, was found to have values between $4.6 \mathrm{~ms}^{-1}$ and $8.6 \mathrm{~ms}^{-1}$. The annual mean $V_{m p}$ and $V_{\max . E}$ for the sites were, respectively, in the range 3.9-7.8 $\mathrm{ms}^{-1}$ and 5.3-9.4 $\mathrm{ms}^{-1}$.

Seasonal variability is evident in wind direction, mainly reflecting monsoon characteristics in the region: in winter and autumn, winds were predominantly from the north, with a considerable northeasterly contribution, while southerly winds prevailed in summer. The prevailing wind direction distribution in the rim is good for energy exploiting and usage. Statistical estimates suggest that a wind farm with 100 turbines each of $5 \mathrm{MW}$ capacity would contribute about $0.8 \%$ and $3.6 \%$ of the total electricity consumption in 2017 for Guangxi and Hainan provinces, respectively.

Overall, this study suggests that China, including the Beibu Gulf, has relatively large resources of offshore wind energy that can reduce its dependency on imported fossil fuels, thus ensuring security of energy supply as well as reduced GHG emissions in the Beibu Gulf Economic Rim, China and the world.

Finally, it should be stated that there was a data loss of more than $20 \%$ in the measurement records at three of the seven stations (i.e., 24\%, 28\% and $23 \%$, respectively, for stations $\mathrm{BX}, \mathrm{DM}$ and $\mathrm{XY}$ ) used in this study. Estimates of wind 
1 speed and wind power variability may be influenced by gaps in the data. We wish to

2 state, for the record, that the analysis of the present study is meant as a first pass only

3 at estimating the viable offshore wind resource in order to highlight the rich offshore

4 wind resource available for the study region. Better and more reliable datasets are needed for follow-up work. Once these improved datasets become available for the region, further analysis will be undertaken using the latest offshore wind turbine parameters.

\section{Acknowledgements}

Xinping Chen was funded by the National Natural Science Foundation of China (NSFC) grant 41506042. Aoife Foley was supported by the Northern Ireland "Department for Economics USI 110 US \& Ireland R\&D Research Partnership" under the US-Ireland Research and Development Partnership program Science Foundation Ireland and the United States National Science Foundation Collaborative Research Decentralisation, ElectrificatioN, Communications and Economics (CREDENCE) Centre-to-Centre Award.

\section{Reference}

[1]Perveen R, Kishor N, Mohanty SR. Off-shore wind farm development: Present status and challenges. Renew Sustain Energy Rev 2014;29:780-92.

[2]Rodrigues S, Restrepo C, Kontos E, Teixeira Pinto R, Bauer P. Trends of offshore wind projects. Renew Sustain Energy Rev 2015;49:1114-35.

[3](GWEC) GWEC. Global Wind Energy Outlook | 2016. 2016.

[4]Wind Europe. Wind energy in Europe: Outlook to 2020. Wind Eur 2017;September 2017.

[5](GWEC) GWEC. Global Wind Report Annual Market Update. 2018.

[6]REN21. RENEWABLES 2015: Global Status Report (the Renewable Energy Policy Network for the 21 st Century). 2015.

[7]Esteban MD, Diez JJ, López JS, Negro V. Why offshore wind energy? Renew Energy 2011;36:444-50. 
1 [8]Bilgili M, Yasar A, Simsek E. Offshore wind power development in Europe and its comparison with onshore counterpart. Renew Sustain Energy Rev 2011;15:905-15.

[9]J.Dvorak M, L.Archer C, Z.Jacobson M. California offshore wind energy potential. Renew Energy 2010;35:1244-54.

[10]Dvorak MJ, Corcoran BA, Hoeve JE Ten, Mcintyre NG, Jacobson MZ. US East Coast offshore wind energy resources and their relationship to peak-time electricity demand 2013;16:977-97.

[11]Iglesias G, Carballo R. Offshore and inshore wave energy assessment: Asturias (N Spain). Energy 2010;35:1964-72.

[12]Colmenar-santos A, Perera-perez J, Borge-diez D. Offshore wind energy : A review of the current status, challenges and future development in Spain. Renew Sustain Energy Rev 2016;64:1-18.

[13]Agency EE, EEA. Europe's onshore and offshore wind energy potential. vol. 6. 2009. doi:10.2800/11373.

[14]Shu ZR, Li QS, Chan PW. Investigation of offshore wind energy potential in Hong Kong based on Weibull distribution function. Appl Energy 2015;156:362-73.

[15]Langodan S, Viswanadhapalli Y, Dasari HP, Knio O, Hoteit I. A high-resolution assessment of wind and wave energy potentials in the Red Sea. Appl Energy 2016;181:244-55.

[16]Cavazzi S, Dutton AG. An Offshore Wind Energy Geographic Information System (OWE-GIS) for assessment of the UK' s offshore wind energy potential. Renew Energy 2016;87:212-28.

[17] Sequeira C, Jerez S. An evaluation of offshore wind power production by floatable systems : A case study from SW Portugal 2017;131.

[18]Kalogeri C, Galanis G, Spyrou C, Diamantis D, Baladima F, Koukoula M, et al. Assessing the European offshore wind and wave energy resource for combined exploitation. Renew Energy 2017;101:244-64.

[19]Kim T, Park J-I, Maeng J. Offshore wind farm site selection study around Jeju Island, South Korea. Renew Energy 2016;94:619-28.

[20]Oh K-Y, Kim J-Y, Lee J-K, Ryu M-S, Lee J-S. An assessment of wind energy potential at the demonstration offshore wind farm in Korea. Energy 2012;46:555-63.

[21]Nagababu G, Kachhwaha SS, Naidu NK, Savsani V. Application of reanalysis data to estimate offshore wind potential in EEZ of India based on marine ecosystem considerations. Energy 2016;118:622-31.

[22] Gadad S, Deka PC. Offshore wind power resource assessment using Oceansat-2 scatterometer data at a regional scale. Appl Energy 2016;176:157-70. 
[23]Nagababu G, R RS, Naidu NK, Kachhwaha SS. Application of OSCAT satellite data for offshore wind power potential assessment of India. Energy Procedia 2016;90:89-98.

[24]Nagababu G, Kachhwaha SS, Savsani V. Estimation of technical and economic potential of offshore wind along the coast of India. Energy 2017;138:79-91.

[25]Bates A, Firestone J. A comparative assessment of proposed offshore wind power demonstration projects in the United States. Energy Res \\& Soc Sci 2015;10:192-205.

\section{[26] Waewsak J, Landry M, Gagnon Y. Offshore wind power potential of the Gulf of Thailand. Renew} Energy 2015;81:609-26.

[27]Chancham C, Waewsak J, Gagnon Y. Offshore wind resource assessment and wind power plant optimization in the Gulf of Thailand. Energy 2017;139:706-31.

[28]Watts D, Oses N, Pérez R. Assessment of wind energy potential in Chile: A project-based regional wind supply function approach. Renew Energy 2016;96:738-55.

[29]Mattar C, Borvarán D. Offshore wind power simulation by using WRF in the central coast of Chile. Renew Energy 2016;94:22-31.

[30]Amirinia G, Ma S, Mazaheri S. Offshore wind resource assessment of Persian Gulf using uncertainty analysis and GIS 2017;113:915-29.

[31]Carvalho D, Rocha A, Gómez-Gesteira M, Silva Santos C. Offshore wind energy resource simulation forced by different reanalyses: Comparison with observed data in the Iberian Peninsula. Appl Energy 2014;134:57-64.

[32]Carvalho D, Rocha A, Gómez-Gesteira M, Silva Santos C. Offshore winds and wind energy production estimates derived from ASCAT, OSCAT, numerical weather prediction models and buoys A comparative study for the Iberian Peninsula Atlantic coast. Renew Energy 2017;102:433-44.

[33] Soares PMM, Lima DCA, Cardoso RM, Nascimento ML, Semedo A. Western Iberian offshore wind resources : More or less in a global warming climate? Special Report on Emissions Scenarios. Appl Energy 2017;203:72-90.

[34]Lima DKS, Leão RPS, dos Santos ACS, de Melo FDC, Couto VM, de Noronha AWT, et al. Estimating the offshore wind resources of the State of Ceará in Brazil. Renew Energy 2015;83:203-21. [35]Rodrigues A, Mendonça F, Trevenzoli A, Helena M, Spyrides C. Complementarity of Brazil 's hydro and offshore wind power. Renew Sustain Energy Rev 2016;56:413-27.

[36]Li J, Gao H, Shi P, Shi J, Ma L, Qin H. China wind power report 2007. 2007.

[37]Rajgor G. China gets serious on offshore wind. Renew Energy Focus 2010;11:16-9. 
[38]Han J, Mol APJ, Lu Y, Zhang L. Onshore wind power development in China: Challenges behind a successful story. Energy Policy 2009;37:2941-51.

[39]Jiang D, Zhuang D, Huang Y, Wang J, Fu J. Evaluating the spatio-temporal variation of China's offshore wind resources based on remotely sensed wind field data. Renew Sustain Energy Rev $2013 ; 24: 142-8$.

[40]Zhang D, Zhang X, He J, Chai Q. Offshore wind energy development in China: Current status and future perspective. Renew Sustain Energy Rev 2011;15:4673-84.

[41]Zhou W, Yang H, Fang Z. Wind power potential and characteristic analysis of the Pearl River Delta region, China. Renew Energy n.d.;31.

[42]Li G. Feasibility of large scale offshore wind power for Hong Kong - A preliminary study. Renew Energy 2000;21:387-402.

[43]Lu L, Yang H, Burnett J. Investigation on wind power potential on Hong Kong islands-an analysis of wind power and wind turbine characteristics. Renew Energy 2002;27:1-12.

[44]Gao X, Yang H, Lu L. Study on offshore wind power potential and wind farm optimization in Hong Kong. Appl Energy 2014;130:519-31.

[45]Chen X, Wang K, Zhang Z, Zeng Y, Zhang Y, Driscoll KO. An assessment of wind and wave climate as potential sources of renewable energy in the nearshore Shenzhen coastal zone of the South China Sea. Energy 2017;134:789-801.

[46]Li D, Geyer B, Bisling P. A model-based climatology analysis of wind power resources at 100-m height over the Bohai Sea and the Yellow Sea. Appl Energy 2016;179:575-89. doi:10.1016/j.apenergy.2016.07.010.

[47] China Energy Statistical Yearbook. (2008-2017). National Bureau of Statistics of China.

[48]China's Action Plan on Prevention and Control of Air Pollution. 2013.

[49]Panofsky HA, Dutton JA. Atmospheric turbulence. Models and methods for engineering applications. 1988.

[50]Kwon S-D. Uncertainty analysis of wind energy potential assessment. Appl Energy 2010;87:856-65.

[51]Islam MR, Saidur R, Rahim NA. Assessment of wind energy potentiality at Kudat and Labuan, Malaysia using Weibull distribution function. Energy 2011;36:985-92.

[52]Eskin N, Artar H, Tolun S. Wind energy potential of Gokceada Island in Turkey. Renew Sustain Energy Rev 2008;12:839-51. 
1. In this study, a comprehensive statistical assessment on wind energy potential in the Beibu Gulf region of the South China Sea was conducted for the period 2010 to 2017.

2. Wind power development in the study area has its own unique advantages, including policy and geographic advantages.

3. Results display evidence of seasonal variability in wind speed and direction, while no significant interannual variability or trends were identified for the period 2010-2017.

4. The Beibu Gulf evidently has vast resources of offshore wind energy that will reduce its dependency on imported fossil fuels such as natural gas. 